\title{
Calculation of Spotting Particles Maximum Distance in Idealised Forest Fire Scenarios
}

\author{
José C. F. Pereira, José M. C. Pereira, André L. A. Leite, and Duarte M. S. Albuquerque \\ IDMEC, Instituto Superior Tecnico, Universidade de Lisboa, Avenida Rovisco Pais, 1049-001 Lisbon, Portugal \\ Correspondence should be addressed to José C. F. Pereira; jcfpereira@tecnico.ulisboa.pt
}

Received 19 January 2015; Revised 13 May 2015; Accepted 24 May 2015

Academic Editor: Michael A. Delichatsios

Copyright (C) 2015 José C. F. Pereira et al. This is an open access article distributed under the Creative Commons Attribution License, which permits unrestricted use, distribution, and reproduction in any medium, provided the original work is properly cited.

\begin{abstract}
Large eddy simulation of the wind surface layer above and within vegetation was conducted in the presence of an idealised forest fire by using an equivalent volumetric heat source. Firebrand's particles are represented as spherical particles with a wide range of sizes, which were located into the combustion volume in a random fashion and are convected in the ascending plume as Lagrangian points. The thermally thin particles undergo drag relative to the flow and moisture loss as they are dried and pyrolysis, charcombustion, and mass loss as they burn. The particle momentum, heat and mass transfer, and combustion governing equations were computed along particle trajectories in the unsteady $3 \mathrm{D}$ wind field until their deposition on the ground. The spotting distances are compared with the maximum spotting distance obtained with Albini model for several idealised line grass or torching trees fires scenarios. The prediction of the particle maximum spotting distance for a $2000 \mathrm{~kW} / \mathrm{m}$ short grass fire compared satisfactorily with results from Albini model and underpredicted by $40 \%$ the results for a high intensity $50000 \mathrm{~kW} / \mathrm{m}$ fire. For the cases of single and four torching trees the model predicts the maximum distances consistently but for slightly different particle diameter.
\end{abstract}

\section{Introduction}

Spot fires occur during wild forest fires when burning debris transported by the wind and convection column land far from the active fire source. Under such occurrence there is a probability to ignite another fire with dangerous consequences for fire brigades and firefighting which should be considered by the decision support systems for wildfire management and planning [1-3]. Many firebrand transport models have been developed; see the pioneers' works of Tarifa et al. [4], Lee and Hellman [5], and Albini [6]. Albini model predicts the maximum spotting distance [6-10] and has been included in several forest fire propagation models [11-17]. The computing time required to obtain predictions with the Albini model is much faster than real time, due to the inherent model based correlations. This is a great advantage over multidimensional Computational Fluid Dynamics (CFD) predictions; however it is believed that forest fire phenomena will benefit from CFD like for enclosure fire predictions; see, for example, [18-20].

The problem is of great complexity because a large number of random parameters are presented. The transport of firebrands involves several modelling difficulties: firstly the knowledge of the particle shape and size that lift off in the flame region; secondly the particle transport by unsteady wind and convection column fields; and last but not the least the probability to ignite a fire after particle landing. This work is only related to the transport of firebrand aiming to predict the particle maximum spotting distance. However it involves the coupled prediction of (i) the wind flow through and above vegetation; (ii) the fire source near region and convection column; and (iii) the particle heat and mass transfer and combustion along its trajectory.

The wind flow interaction with canopy trees has been extensively studied [21-25]. The vertical mean wind velocity displays an exponential profile type inside the forest and the turbulence levels are mainly due to turbulent kinetic energy production by shear at the canopy top, rather than by wake production by the individual elements. The flow within and above a forest is linked by turbulent motions, at larger scales relative to the forest depth, that are strongly intermittent in character [22, 26, 27]. Several attempts have been proposed to simulate the exchanges between a forest 
and the lower atmosphere by assembling averaged statistical turbulent models such as $k-\varepsilon$; see [28-31]. These models are inadequate in representing the intermittent character of the flow. Large eddy simulation (LES) explicitly simulates the dominant energetic turbulent scales resolved by the threedimensional mesh [32-34] and consequently it was used in this work.

Due to the disparity of scales in the fire heat release region from those of the remaining computational domain, it is almost impossible to resolve and to predict the heat release rate, but it is to be given as an input parameter. The so-called Lagrangian thermal elements $[35,36]$ are used to model the fire release heat as they are convected about by the thermal induced motion. Under this assumption, the fire is a large collection of blobs carried along by the largescale motion and the heat release rate associated with each element is represented by a simple function with a time scale determined from the plume correlations summarised by [37]. A far more simplified model is to prescribe a heat source either on the surface or in volume, usually approximated by Gaussian profiles [38] and by correlations of the flame height as a function of the firepower intensity. This was the procedure adopted to model the fire itself and the source was assumed stationary since the propagation fire velocity is small compared with the wind velocity.

The pioneers' works have employed the classical plume model approach of integral models to predict buoyant plumes in a cross flow responsible for firebrand lofting. Examples of developed simplified models are for initially axisymmetric jets $[39,40]$ and for buoyant plumes from fires $[5,7,9]$ or integral plume models for line fires in a cross flow [41]. These models reduce the problem to a set of ordinary differential equations to be solved with an approximate expression or with an empirical fit to calculate the plume trajectory, width, velocity, and temperature. Three-dimensional field calculations of fire plumes have been extensively investigated; see, for example, [36, 38, 42]. In this work the latter approach is followed and a LES model was selected that takes into account explicitly the subgrid stresses and turbulent heat fluxes [43].

In the framework of time averaged turbulent flow modelling, the problem of the instantaneous velocity acting on the particle is usually treated under Lagrangian stochastic models; see [44] for a review. For the present purpose of the LES calculations during the firebrand trajectory it was assumed that the calculated instantaneous velocity field acts in the particle during the considered time step. There are three main ways on how to account with the with the wind interaction in the firebrands particles. The first way is to consider spherical particles with a wide range of sizes undergoing drag relative to the flow and moisture loss as they are dried and pyrolysis, char-combustion, and mass loss as they burn. Models to calculate flight paths of dispersed particles in a turbulent flow are well established and a spherical particle shape is assumed due to inherent difficulties to know the drag and momentum coefficients from other shapes; see, for example, [45]. The second way is to consider nonspherical particles shapes, cylinders or discs, under one-way coupling, meaning that the wind influences the nonspherical particle orientation relative to the local wind obtained by momentum balances, but with prescribed drag and momentum coefficients as a function of relative particle orientation. The third one would correspond to the intrusive real body geometry of the nonspherical particle and the calculation (with Chimera or moving meshes) of their wake that may interfere with the particle itself during tumbling, fluttering, or chaotic free fall motion.

Recently, experimental apparatus has been constructed in order to generate a controlled size and mass distribution of glowing firebrands; see, for example, [46, 47], allowing studying the combustibility of firebrand material such as pine cones and scales and pieces of bark eucalypt; see [48]. Theoretical models for the drag coefficient of nonspherical particles are being established (see [49-51]) but the wide range of random shapes, sizes, and terminal velocities requires validation tests before practical use in reactive multidimensional calculations.

The combustion model of the woody, cellulose, or coal fuel particles commonly includes drying, pyrolysis, and charoxidation processes. Their burning characteristics and diameter at landing are related to the potential for the firebrand to ignite the adjacent vegetation [52-55] and reviews of the modelling chemical and physical processes of wood and biomass pyrolysis have been presented; see, for example, [56-58]. Firebrand propagation prediction is based on either plume model, coupled fire-atmosphere, or semiempirical models to predict the fire spread; see, for example, [5961]. Particles trajectories and spotting distances have been obtained for a wide range of idealised cases using these main assumptions about the fire source responsible for the convection column; see, for example, [55, 61-63].

Physics based on coupled fire-atmosphere models consider approximations of the governing equations from the fluid dynamics, the combustion, and the thermal degradation of solid fuel (see, e.g., [64-66]) aiming to preclude the use of existing simplified empirical wildfire models because they do not predict general fire behaviour; however the high-resolution and the high-fidelity combustion are not currently appropriate because of their computational cost. Several physics based on coupled fire-atmosphere studies have been conducted (see [67-72]) and some of these studies have been applied to the fire spotting problem. Among them [71] has considered particle combustion of cylindrical and disk-shaped firebrands for several geometrical parameters. Discs travel further than cylinders; also firebrands from canopy fires travel further than firebrands from surface fires. Depending on where the burning occurs, for example, the faces or around their circumference, this influences the firebrand lifetimes. In addition the simulations reveal that the coupled fire-atmosphere behaviour dominates the trajectories and landing patterns.

The main difficulty in the validation of the Albini model or of a CFD model, under real conditions, is that large field forest fires only show the spotting fires signature on the ground after the fire has been extinguished and it is unknown if they correspond to the particle maximum spotting distance. The particle responsible for the maximum spotting distance may not ignite a fire in opposition to the other particles that 
spot too much shorter distances. Consequently the intercomparison of different models may contribute to estimating the error bar of the spotting distances pattern.

The main objective of this work is to compare the maximum spotting distance obtained with the Albini model with the spotting particles maximum distance obtained with LES and firebrand combustion models. Therefore in this work a coupled solution of the three-dimensional velocity and temperature unsteady fields is obtained and for each time step the particles are allowed to burn during their convection. For each particle size the calculated spotting distances as well as their char, ash, and temperature allow one to obtain the maximum spotting distance for a prescribed fire. Two classes of fires are presented: grass fires and burning of trees. For both cases the predicted maximum spotting distances are compared with Albini model's results.

In the next section the models are briefly presented. The section of Results follows this, but prior to the firebrand transport results a LES benchmark test case was performed. It corresponds to the LES simulation of lower atmosphere with a homogeneous forest [22] to investigate the LES solution dependence on coarse grid resolution. Next, firebrand spotting is examined using a coupled fire/atmosphere LES (large eddy simulation) in which the processes of firebrand lofting, propagation, and deposition are connected. The idealised scenarios correspond to the Albini "spotting distance examples" [6] for short grass $2000 \mathrm{~kW} / \mathrm{m}$ fire and wind-driven fire in chaparral $50000 \mathrm{~kW} / \mathrm{m}$ fire. In addition torching trees were considered, based on the scenario given by [73], the first corresponding to a single Grand Fir tree and the second corresponding to four trees burning together. The paper closes with summary conclusions about the comparison of the maximum spotting distances.

\section{Mathematical and Numerical Model}

2.1. Governing Equation. The governing equations are the continuity Navier-Stokes and energy equations. The Boussinesq approximation is used and the equations include additional terms to account for the drag from the canopy trees and for the heat received by the air in contact with the vegetation. The filtered Navier-Stokes model equations can be expressed by

$$
\begin{aligned}
& \frac{\partial \bar{u}_{j}}{\partial x_{j}}=0, \\
& \begin{aligned}
\frac{\partial \bar{u}_{i}}{\partial t}+\frac{\partial\left(\bar{u}_{j} \bar{u}_{i}\right)}{\partial x_{j}}= & \frac{1}{\rho} \frac{\partial \bar{p}}{\partial x_{i}}+\frac{\partial \bar{p}}{\partial x_{j}}\left(v \frac{\partial \bar{u}_{i}}{\partial x_{j}}-\overline{u_{i}^{\prime \prime} u_{j}^{\prime \prime}}\right)+\beta g T \delta_{i 3} \\
& +F_{i}, \quad i=1,2,3,
\end{aligned}
\end{aligned}
$$

$$
\begin{aligned}
\frac{D \bar{T}}{D t} & \equiv \frac{\partial \bar{T}}{\partial t}+\frac{\partial\left(\bar{u}_{j} \bar{T}\right)}{\partial x_{j}} \\
& =\frac{\partial}{\partial x_{j}}\left(\mu \frac{\partial \bar{T}}{\partial x_{j}}-\overline{u_{j}^{\prime \prime} T^{\prime \prime}}\right)+S_{h}+S_{R} .
\end{aligned}
$$

Here $p$ is the pressure, $g$ is the gravitational acceleration, $\beta=$ $-(\partial \rho / \partial T)_{p} / \rho$ is the volumetric expansion coefficient, and $n$ and $m$ are the constant molecular diffusivities of momentum and heat. The bar denotes the average over a computational grid cell and the double primes the deviations thereof. The Coriolis force has been excluded as it has little direct bearing on scales of motion for the domain considered of the order of $1 \mathrm{~km}$.

2.2. The Subgrid-Scale (SGS) Model. There is a wide range of subgrid-scale (SGS) models as well as great knowledge of the modelling issues like gradient-diffusion hypothesis used in some of the large eddy simulations; see, for example, $[74,75]$. For atmospheric flows the pioneer classical models (see, e.g., $[33,34]$ ) have been being improved with models based on transport equations for the SGS stresses and fluxes. The second-order closure subgrid-scale equations model reported by [43] was selected for the present purpose to predict a plume at cross flow in the atmospheric surface layer. The model uses a transport equation for the subgrid-scale kinetic energy $\overline{E^{\prime \prime}} \equiv \overline{u_{i}^{\prime \prime 2}} / 2$

$$
\begin{aligned}
\frac{D \overline{E^{\prime \prime}}}{D t}= & -\overline{u_{i}^{\prime \prime} u_{j}^{\prime \prime}} \frac{\partial \bar{u}_{i}}{\partial x_{j}}+\beta g \overline{w^{\prime \prime} T^{\prime \prime}}+\frac{\partial}{\partial x_{i}}\left[\frac{5}{3} l c_{3 m} \overline{E^{\prime \prime}} \frac{1 / 2}{\partial \bar{E}^{\prime \prime}}\right. \\
& -c_{\varepsilon m} \frac{{\overline{E^{\prime \prime}}}^{3 / 2}}{l}-2 \frac{\overline{E^{\prime \prime}}}{\tau} .
\end{aligned}
$$

The turbulent heat and momentum fluxes and their respective anisotropic components,

$$
\overline{A_{i j}^{\prime \prime}}=\overline{u_{i}^{\prime \prime} u_{j}^{\prime \prime}}-\frac{2}{3} \delta_{i j} \overline{E^{\prime \prime}}, \quad i=1,2,3, \quad j=1,2,3,
$$

are determined from the following set of algebraically approximated second-order closure equations:

$$
\begin{aligned}
0= & -\left(1-c_{G m}\right) \frac{2}{3} \overline{E^{\prime \prime}}\left(\frac{\partial \bar{u}_{i}}{\partial x_{i}}+\frac{\partial \bar{u}_{j}}{\partial x_{i}}\right)+\left(1-c_{B m}\right) \\
& \cdot\left[\beta g\left(\delta_{i 3} \overline{u_{j}^{\prime \prime} T^{\prime \prime}}+\delta_{j 3} \overline{u_{j}^{\prime \prime} T^{\prime \prime}}-\frac{2}{3} \delta_{i j} \overline{u_{3}^{\prime \prime} T^{\prime \prime}}\right)\right]-c_{R m} \\
& \cdot \frac{E^{\prime \prime 1 / 2}}{l} \overline{A_{i j}^{\prime \prime}}, \\
0= & -\left(1-c_{G T}\right) \frac{2}{3} \overline{E^{\prime \prime}} \frac{\partial \bar{T}}{\partial x_{i}}+\left(1-c_{B T}\right) \beta g \overline{T^{\prime \prime 2}} \delta_{i 3}-c_{R T} \\
& \frac{E^{\prime \prime 1 / 2}}{l} \overline{u_{i}^{\prime \prime} T^{\prime \prime}}, \\
0= & -2 \overline{u_{j}^{\prime \prime} T^{\prime \prime}} \frac{\partial \bar{T}}{\partial x_{j}}-c_{\varepsilon T} \frac{E^{\prime \prime 1 / 2} T^{\prime \prime 2}}{l} .
\end{aligned}
$$


Equations (6a) to (6c) were solved explicitly as proposed by [43] yielding

$$
\begin{aligned}
\overline{A_{i j}^{\prime \prime}} & =\frac{l}{c_{R m} \overline{E^{\prime \prime 1 / 2}}}\left[\left(1-c_{G m}\right) \frac{2}{3} \overline{E^{\prime \prime}}\left(\frac{\partial \bar{u}_{i}}{\partial x_{j}}+\frac{\partial \bar{u}_{j}}{\partial x_{i}}\right)+\overline{B_{i j}^{\prime \prime}}\right], \\
\overline{B_{i j}^{\prime \prime}} & =\left(1-c_{B m}\right) \beta g\left(\overline{u_{j}^{\prime \prime} T^{\prime \prime}} \delta_{i 3}+\overline{u_{i}^{\prime \prime} T^{\prime \prime}} \delta_{j 3}\right. \\
& \left.-\frac{2}{3} \delta_{i j} \overline{u_{3}^{\prime \prime} T^{\prime \prime}}\right), \\
\overline{u_{i}^{\prime \prime} T^{\prime \prime}} & =-\frac{l}{c_{R T} \overline{E^{\prime \prime 1 / 2}}}\left[\left(1-c_{G T}\right) \frac{2}{3} \overline{E^{\prime \prime}} \frac{\partial \bar{T}}{\partial x_{i}}\right. \\
- & \left.\left(1-c_{B T}\right) \beta g \overline{T^{\prime \prime 2}} \delta_{i 3}\right] \\
\overline{T^{\prime \prime 2}} & =-\frac{2 l}{c_{\varepsilon T} \overline{E^{\prime \prime 1 / 2}}}\left[\overline{u_{i}^{\prime \prime} T^{\prime \prime}} \frac{\partial \bar{T}}{\partial x_{i}}\right] .
\end{aligned}
$$

The coefficients of the SGS model are listed in Table 1 according to [43].

The length scale $l$ is prescribed as a function of height above the ground surface and of the mesh size $\Delta$ :

$$
l=\min \left(\Delta, c_{l} z\right), \quad \Delta=\frac{1}{3}(\Delta x+\Delta y+\Delta z) .
$$

The numerical stability enhanced procedures described by [76] were used to solve (4).

A second SGS model was also considered, the classic Smagorinsky [77] model, because it is used extensively in atmospheric boundary layer predictions. The simple Smagorinsky subgrid-scale model should be sufficient provided that the temporal and spatial resolution is fine enough to resolve a major fraction of the energetic scales; see, for example, [78]. These resolution requirements become computationally not feasible in higher resolutions and especially in proximity to the surface.

2.3. Additional Terms to Model the Forest. The additional term $\left(F_{i}\right)$ in (2) represents the drag force due to the canopy modelled as a porous body of uniform area density. The drag force was taken according to [18] as time dependent and equal to the product of the local foliage density (a function only of the vertical position), a constant drag coefficient $C_{D}=0.15$, and the square of the local velocity such that the force $F_{i}$ the $x_{i}$-direction is given by

$$
F_{i}=-C_{D} a V \bar{u}_{i}=-\frac{\bar{u}_{i}}{\tau}
$$

where $V$ is scalar speed. The drag coefficient is isotropic and the drag force directly opposes the local, instantaneous wind vector.

The $S_{h}$ term in (3) takes into account the heat source provided by the foliage that is heated by assuming that solar radiation penetrates the canopy and warms the foliage. The strength of the heat source, $S_{h}$, included in (3) is then the
TABLE 1: Coefficients of the SGS model.

\begin{tabular}{ccccccccc}
\hline$c_{3 m}$ & $c_{\varepsilon m}$ & $c_{G m}$ & $c_{B m}$ & $c_{R m}$ & $c_{G T}$ & $c_{R T}$ & $c_{\varepsilon T}$ & $c_{l}$ \\
\hline 0.2 & 0.845 & 0.55 & 0.55 & 3.5 & 0.5 & 1.63 & 2.02 & 0.845 \\
\hline
\end{tabular}

vertical derivative of the upward kinematic vertical heat flux given by

$$
\begin{aligned}
& Q(z)=Q(h) \exp (-\alpha F), \\
& \text { and } F \text { given by } F=\int_{z}^{h} L d z,
\end{aligned}
$$

where $F$ is the downward cumulative leaf area index (nondimensional), which is an extinction coefficient and is taken to be 0.6 . Only the test case corresponding to weakly convective conditions, $Q(h)=0.005$, was considered corresponding to $W_{k} / U_{k}=1.1$, where $W_{k}$ is the convective velocity scale $\left[W_{k}=\right.$ $\left.(\beta g Q(h) 2 h)^{1 / 3}\right]$, and $h / l=-0.26$, where $l$ denotes the MoninObukhov length and the leaf area densities, $L$ (integration of the plant area density) considered as described by [43].

The last term in (3) represents the radiative heat source assuming a simplified heat loss:

$$
S_{R}=\varepsilon \sigma\left(T^{4}-T_{0}^{4}\right)
$$

where $\sigma$ denotes the Stefan-Boltzmann constant and the emissivity was assumed equal to $\varepsilon=0.25$.

The last term in (4) represents an additional dissipation process due to canopy drags in which $t$ is a time scale for the drag defined by (9). The term takes into account the removal of SGS kinetic energy by the action of drag on the assumption that wake motions are of even smaller scale than those making up the bulk of SGS kinetic energy.

An extra scalar transport equation to simulate the "smoke concentration" was added only for visualization proposes.

2.4. Firebrand Transport Model. The motion of firebrands is studied by assuming that they behave as a point mass and the aerodynamic drag acts in the opposite direction to the motion of the centre of gravity from the firebrand. Considering only drag and gravity, the three-dimensional motion of a firebrand of mass $m$ moving at the velocity $u_{p}$ within the fire velocity $u_{i}$ is governed by the following system of differential equations:

$$
m \frac{d u_{p i}}{d t}=\frac{1}{2} C_{D} \rho A_{p}\left(u_{i}-u_{p i}\right)\left|u_{i}-u_{p i}\right|-m \cdot g
$$

where the gravity force acts only in the vertical coordinate direction.

The drag coefficient $C_{D}$ depends on the particle shapes. Here a spherical shape is chosen for the firebrand because of the well-known dependence of the drag coefficient with Reynolds number:

$$
\begin{aligned}
& C_{D}=\frac{24}{\operatorname{Re}_{p}}\left(1+0.15 \mathrm{Re}_{p i}^{0.687}\right) \text { for } \operatorname{Re}_{p i} \leq 1000, \\
& C_{D}=0.44 \text { for } \operatorname{Re}_{p i} \geq 1000,
\end{aligned}
$$


where the particle Reynolds number is

$$
\operatorname{Re}_{p i}=\frac{\rho\left|u_{i}-u_{p i}\right| d_{p}}{\mu} .
$$

The particles for the test cases investigated have a range of a few millimetres and they are made of coal and cellulose. The rate of particle mass reduction due to water vaporisation, pyrolysis, and char combustion can be represented by the sum of the mass rates:

$$
\frac{d m_{p}}{d t}=\frac{d \rho_{p} V_{p}}{d t}=\frac{d m_{p}^{\mathrm{H}_{2} \mathrm{O}}}{d t}+\frac{d m_{p}^{\mathrm{pyr}}}{d t}+\frac{d m_{p}^{\text {char }}}{d t} .
$$

During the drying and pyrolysis processes, the volume of the particle is assumed to remain constant and the mass equation reduces to

$$
V_{p} \frac{d \rho_{p}}{d t}=\frac{d m_{p}^{\mathrm{H}_{2} \mathrm{O}}}{d t}+\frac{d m_{p}^{\mathrm{pyr}}}{d t} .
$$

Whilst during char combustion, the particle density is assumed to remain constant and the mass equation reduces to

$$
\rho_{p} \frac{d V_{p}}{d t}=\frac{d m_{p}^{\text {char }}}{d t} .
$$

The rates of mass loss due to dry in [79] and pyrolysis [80] can be deduced from the following Arrhenius-type laws:

$$
\begin{aligned}
\frac{d m_{p}^{\mathrm{pyr}}}{d t} & =-2.67 \times 10^{9} \exp \left(\frac{-17921}{T_{p}}\right) \\
\frac{d m_{p}^{\mathrm{H}_{2} \mathrm{O}}}{d t} & =-6.0 \times 10^{5} T_{p}^{-0.5} m_{p}^{\mathrm{H}_{2} \mathrm{O}} \exp \left(\frac{-6000}{T_{p}}\right) .
\end{aligned}
$$

Following drying and pyrolysis, the particle mass change due to char combustion is given by [56]:

$$
\frac{d m_{p}^{\text {char }}}{d t}=-28.0 \exp \left(\frac{-9646}{T_{p}}\right) \pi d_{p}^{2} P_{\mathrm{O}_{2}}^{0.5},
$$

where $P_{\mathrm{O}_{2}}$ is the pressure of oxygen adjacent to the particle.

By considering the assumption that particles are thermally thin, the temperature throughout any particle is uniform while it is being heated or in combustion. The particle heat conduct (convection) equation reduces to

$$
\begin{aligned}
\frac{d\left(c_{p} m_{p} T_{p}\right)}{\partial t}= & \frac{d m_{p}^{\mathrm{H}_{2} \mathrm{O}}}{d t} Q^{\mathrm{vap}}+\frac{d m_{p}^{\mathrm{pyr}}}{d t} Q^{\mathrm{pyr}} \\
& +\alpha_{c} \frac{d m_{p}^{\text {char }}}{d t} Q^{\mathrm{char}}+Q_{\mathrm{con}}+Q_{\mathrm{rad}}
\end{aligned}
$$

where $\alpha_{c}$ represents the fraction of the particle heat of char combustion, which is transferred to the particle. Here $\alpha_{c}$ $=0.3$. Water vaporisation and pyrolysis are endothermic processes $\left(Q^{\text {vap }}=2.4 \mathrm{KJ} / \mathrm{kg}\right.$ and $\left.Q^{\mathrm{pyr}}=0.418 \mathrm{KJ} / \mathrm{kg}\right)$ whilst

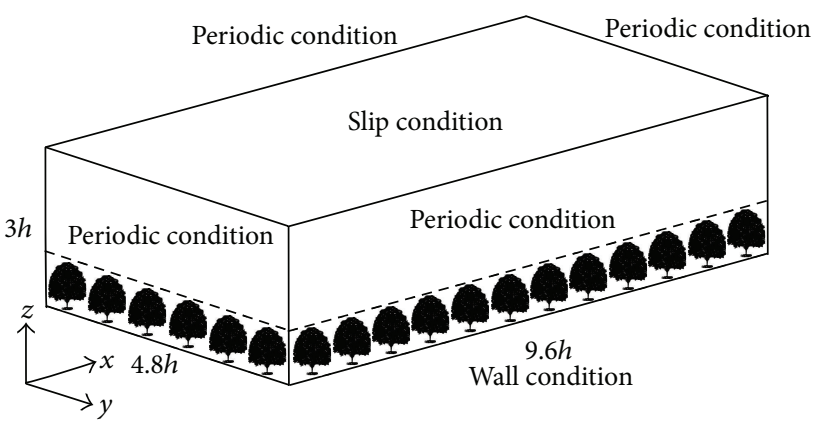

Figure 1: Computational domain of a deciduous forest.

char combustion is highly exothermic $\left(Q^{\text {char }}=-32.74 \mathrm{KJ} / \mathrm{kg}\right)$. The radiative heat transfer between the particle and the gas $Q_{\text {rad }}$ has been neglected here. Convective heat transfer is obtained for a sphere moving at the slip velocity through the gas:

$$
Q_{\text {con }}=\frac{\mathrm{Nu} \lambda}{d_{p}} A_{p}\left(T-T_{p}\right)=\operatorname{Nu} \pi \lambda\left(T-T_{p}\right) d_{p},
$$

where the Nusselt number $\mathrm{Nu}$ is given by

$$
\mathrm{Nu}=2\left(1+0.345 \operatorname{Re}_{p}^{1 / 2} \operatorname{Pr}^{1 / 3}\right) .
$$

The thermal conductivity $\lambda$ is the function of the mean temperature of gas and particle. The Lagrangian approach is used to calculate the particle motion. In this procedure the particle trajectories are integrated considering instantaneous gas mean velocity at each time step.

2.5. Numerical Method and Boundary Conditions. The discretization of the unsteady form of the momentum, energy, and scalar concentration equations was made with a finite volume method together with the QUICKEST discretization scheme [81] that is of 3rd-order accuracy in space and time. The explicit scheme uses quadratic Leith type of temporal discretization and upstream quadratic interpolation involving 21 grid points for the evaluation of the convective fluxes in three-dimensional problems. A Poisson equation was solved to ensure that the velocity field is divergence-free. The maximum Courant number used was equal to 0.5 and details about QUICKEST scheme are given in [82, 83]. Calculations were also obtained with another own developed finite volume code, SOL (see [84, 85]), that employs unstructured meshes and despite having second-order formal accuracy its order of accuracy is likely to be reduced by the use of flux limiters to avoid solution wiggles.

Figure 1 also shows the boundary conditions used in each plane of the block domain; in the streamwise direction a nonperiodic pressure gradient is adjusted in each time step in order to maintain a prescribed mean velocity, with periodic conditions in the planes normal to the streamwise direction.

The boundary conditions employed for the fire scenarios are antisymmetric conditions in the spanwise direction while at inlet a velocity profile was prescribed and at outlet a Sommerfeld wave extrapolation was considered to minimise 
reflection. At the bottom, a nonslip boundary condition is used in which the vertical fluxes of the horizontal momentum are evaluated from the Monin-Obukhov relationship according to [43]. At the top, free-slip boundary conditions are used for the horizontal velocity components and the vertical derivative of temperature and the vertical flux of SGS kinetic energy is set to zero. This artificial boundary condition may be interpreted as a strong inversion. For the homogeneous forest test case periodic boundary conditions are used in the spanwise direction.

\section{Results}

\subsection{Wind Flow above and within a Model Forest}

3.1.1. Velocity Fields. The computational domain extends over $9.6 h \times 4.8 h$ on the ground and over $3 h$ on the vertical of a homogeneous deciduous forest as proposed by [22] (see Figure 1), with $h$ being the tree's height. A leaf area density vertical profile is considered with the distribution reported in the reference that corresponds to leaf area index of 5. A uniform mesh comprising $96 \times 48 \times 30$ mesh nodes was used by [22] that includes 10 grid nodes below the canopy height.

The predictions with the QUICKEST code employ a 5 -node resolution of the tree's height corresponding to $50 \times 26 \times 17$ grid nodes. The coarser mesh was used because spotting distances in the forest fires cases require distances spanning a much wider domain, approximately two orders of magnitude of the tree's height, and for practical situations the resolution used by [22] would be unpractical.

Figure 2 shows the averaged streamwise velocity for a leaf area index equal to 5 . The present predictions show the strong velocity deficit due to trees and the velocity variation with height is in satisfactory agreement with [22]. The predicted vertical profile of turbulence kinetic energy obtained with Smagorinsky is shown in Figure 3(a) and below the canopy the grid resolution is still not enough. But globally it follows in satisfactory agreement the turbulence kinetic energy reported by [22] as well as by the LES transport SGS equation for the subgrid fluxes used in QUICKEST. The subgrid-scale contribution is small and the trend is in satisfactory agreement with the reported values. The results obtained with QUICKEST show some discrepancies with those reported by [22] due to the lack of grid resolution.

Figure 3(b) shows the predicted turbulent shear stress for a leaf area index equal to 5 . The nondimensionalised values, by its value at treetop height, show a satisfactory agreement in the rapid and almost linear decay inside the forest as demanded by the strong drag forces and above the canopy in near-linear fashion forced by the existence a deep mixed layer. Also as shown by [22] the SGS contribution to the Reynolds stress is small, indicating that it is generally a very small component of the total momentum flux. The contribution of the subgrid stress to the total shear stress is very small denoting that the large-scale motion is mainly responsible for the large values observed on the canopy and on the shear flow.

Figures 4(a) and 4(b) show a horizontal slice at the middle of the domain with velocity vectors ( $U$ and $V$ components),

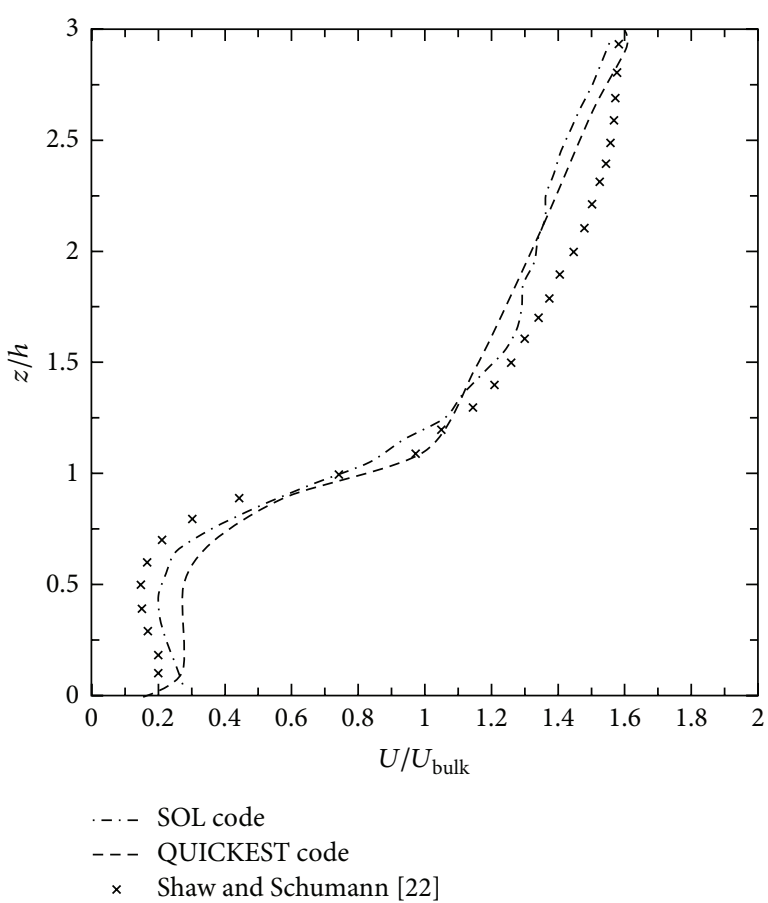

FIGURE 2: Spatial mean longitudinal velocity profiles for a leaf area index equal to 5 .

together with contours of the spanwise and vertical velocity components, respectively. The figures show regions of updrafts and downdrafts due to the intermittent character of large-scale phenomena. Figure 4(c) shows a vertical slice contour plot of $U$ velocity with velocity vectors $(U$ and $W$ components), where the two distinct regions with high and low velocity due to the presence of the forest trees in the bottom of the domain can be observed.

This test case shows that the developed software code with the incorporation of the LES model reproduces satisfactorily the flow within and above the model forest. Although a coarse mesh was used the QUICKEST predictions are in satisfactory agreement with [22]. For the study related to spotting distance from a forest fire we have selected the QUICKEST model with SGS turbulent kinetic energy equation. This still state-of-theart model should perform much better for the plume in cross flow than the SGS eddy diffusivity concept embodied in the Smagorinsky model for the treatment of the SGS heat fluxes.

3.1.2. Particle Dispersion. The homogeneous forest constitutes a good scenario to analyse the dispersion of particles that are released at a certain height above the canopy. Under wind periodic boundary conditions the particle will be transported by the unsteady wind and may experience several domain turnovers up to ground deposition. For this purpose the vertical dimension of the computational domain was doubled and particles were released at 50-metre height. At $t=0$, the initial streamwise and vertical velocity components were assigned to be equal to local wind velocity and the terminal particle velocity, respectively. This scenario without the buoyant plume atmosphere interaction is only relevant 


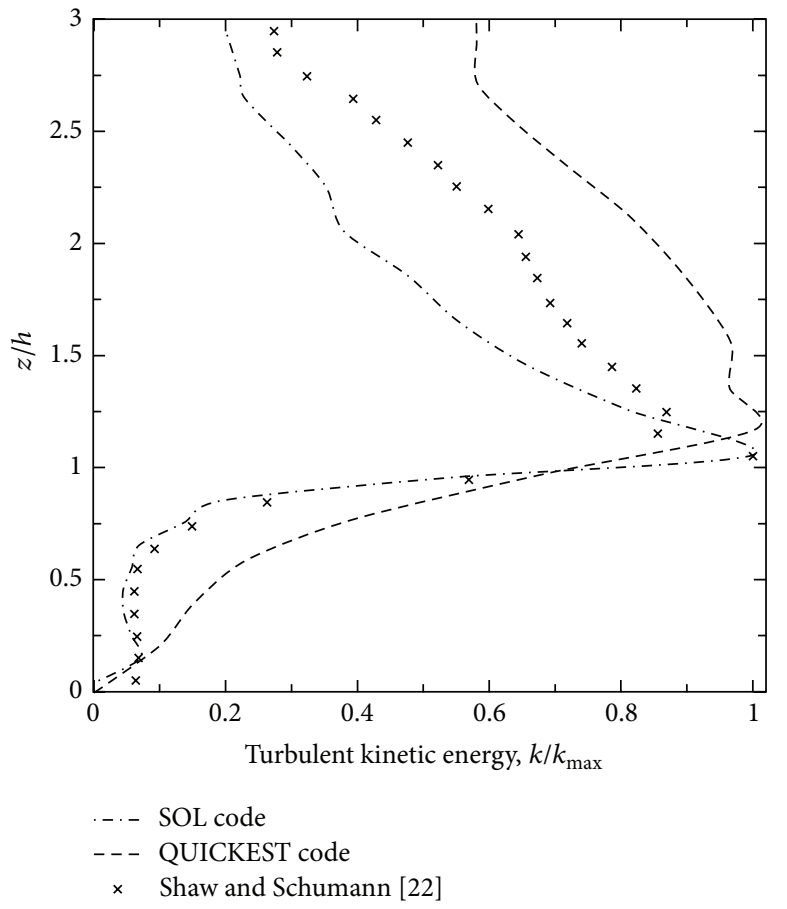

(a)

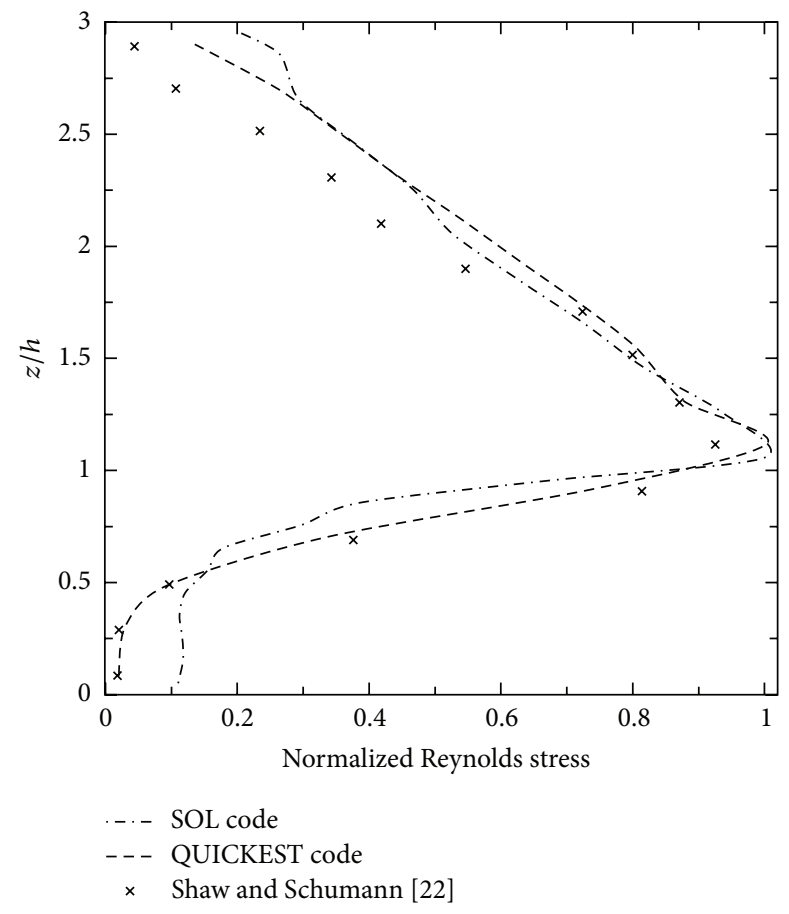

(b)

FIGURE 3: Vertical profile of the turbulent kinetic energy (a) and of the Reynolds stress (b) for a leaf area index equal to 5.

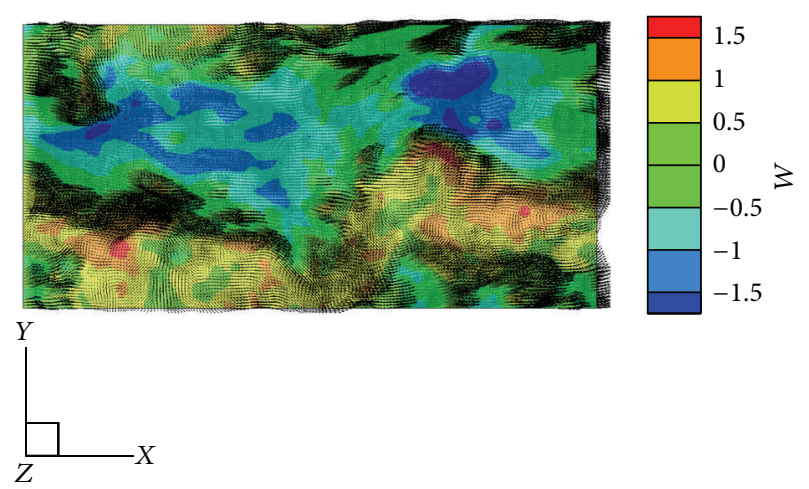

(a)

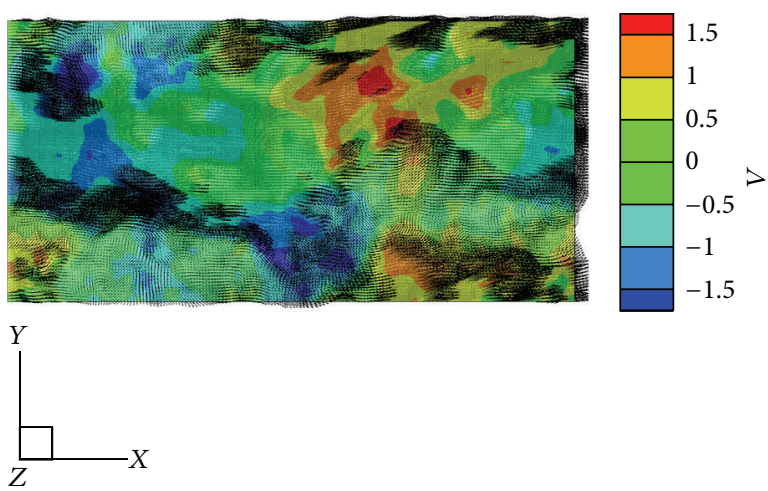

(b)
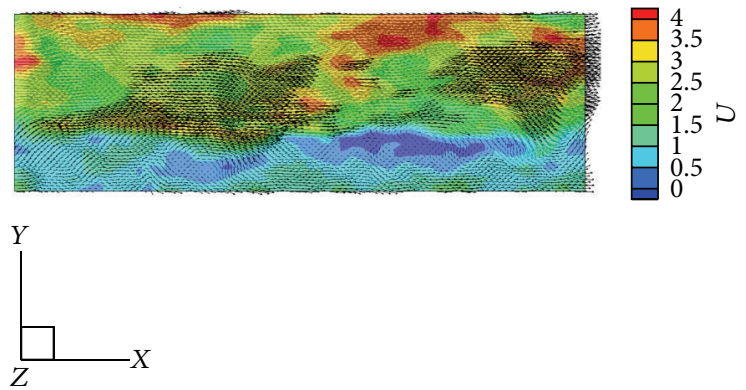

(c)

FIGURE 4: Instantaneous velocity contour plots with velocity vectors: (a) $W$ velocity with slice plane at $Z=25 \mathrm{~m}$; (b) $V$ velocity, slice plane at $Z=25 \mathrm{~m}$; and (c) $U$ velocity, slice plane at $Y=48 \mathrm{~m}$. 


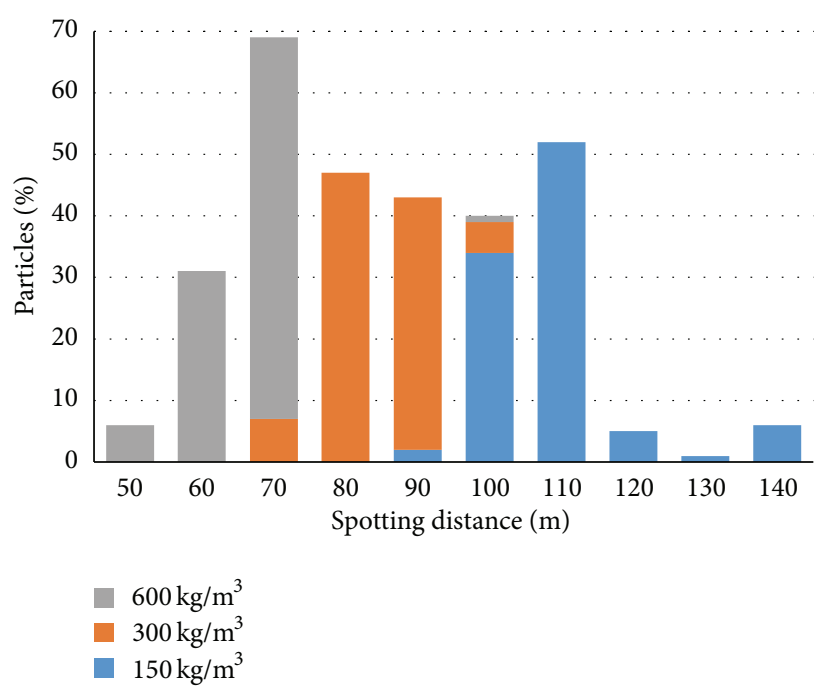

(a)

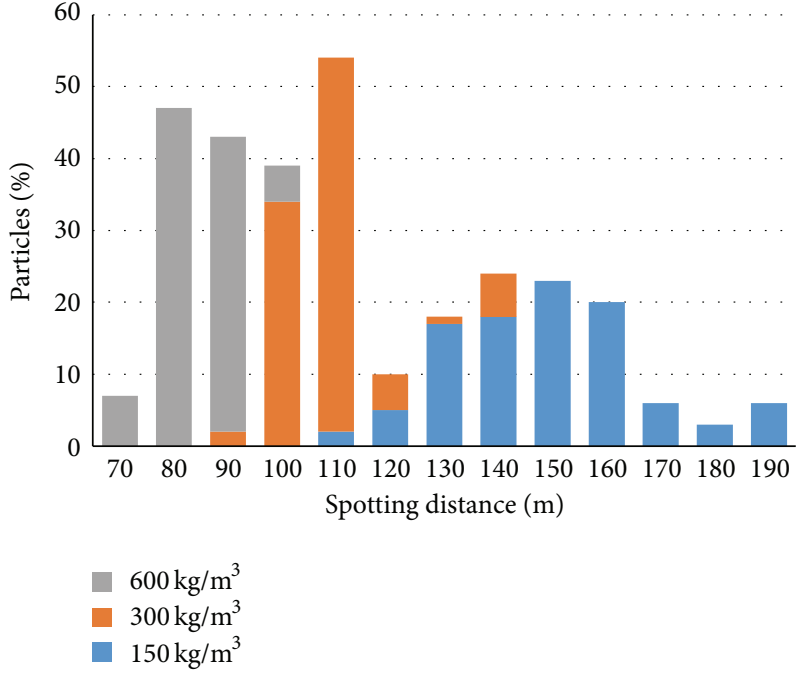

(b)

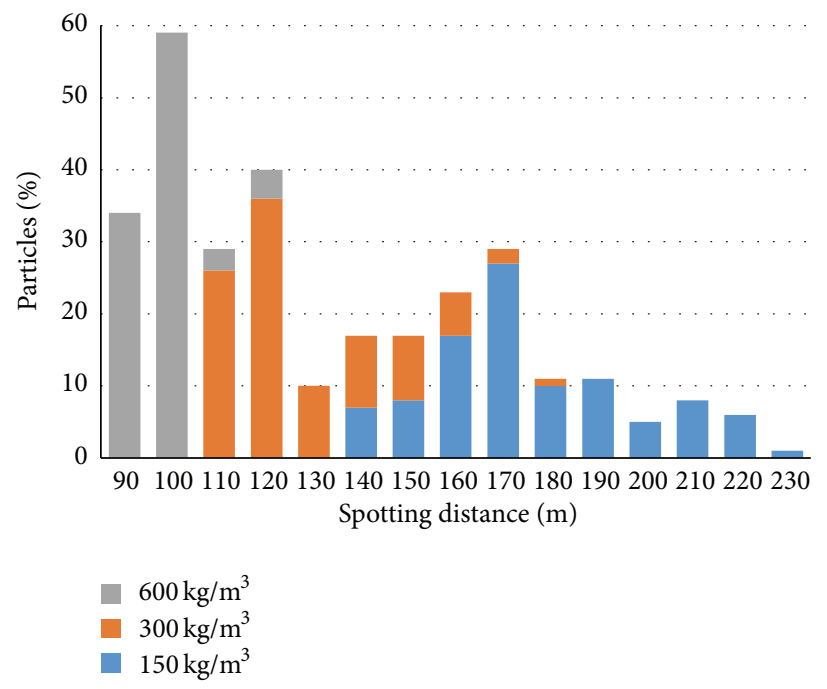

(c)

Figure 5: Spotting distances of the spherical particles for three different densities, 150, 300, and $600 \mathrm{~kg} / \mathrm{m}^{3}$, and three different drag coefficients, (a) $\mathrm{Cd}=0.4$; (b) $\mathrm{Cd}=0.8$; and (c) $\mathrm{Cd}=1.2$.

to simulating the particles final flight path, after leaving the convective column, and their interaction with the canopy dominated flow. In addition the wind velocity was $15 \mathrm{~m} / \mathrm{s}$ to simulate strong winds occurring very often in large fires. The particles were assumed to be spherical with different drag coefficients, $0.4,0.5$, and 1.2 , and densities, $150 \mathrm{~kg} / \mathrm{m}^{3}$, $300 \mathrm{~kg} / \mathrm{m}^{3}$, and $600 \mathrm{~kg} / \mathrm{m}^{3}$, in order to simulate different particle relaxation times.

Figures 5(a), 5(b), and 5(c) show the probabilities of spotting distances for the three drag coefficients, respectively. The light particles travel more and are strongly dependent on the drag coefficient. The high drag force communicates a higher particle momentum in the streamwise direction, and the particles with low density, $150 \mathrm{~kg} / \mathrm{m}^{3}$, have a maximum spotting distance corresponding to $140 \mathrm{~m}$ for $\mathrm{Cd}=0.4$ and reach up to $230 \mathrm{~m}$ for $\mathrm{Cd}=1.2$; the probability density curve denotes the increase of the variability with the increase of drag. For the heavy particles with density $600 \mathrm{~kg} / \mathrm{m}^{3}$ the spotting distances change much less with the considered drag coefficients. It should be mentioned that despite the simplicity of the analysis one identifies a large variability, from 130 to $230 \mathrm{~m}$ for light particles with a realistic $\mathrm{Cd}=1.2$. The liftedoff particles that reach an altitude of $50 \mathrm{~m}$, say by transient events of intense flammability of isolated torching trees, and begin their transport by the wind field outside the convection column may deposit with a large dispersion, creating a large uncertainty of secondary fires.

3.2. Spotting Distances from a Model Fire. In previous subsection quantitative or qualitative comparisons of the predictions were performed concluding that although coarse grids are used the numerical results are still consistent with 
the parameters that influence the transport of large diameter firebrands.

All the predictions that follow use the volumetric heat source strength calculated from

$$
\int I d s=Q=\iiint_{v} q d v,
$$

where $I$ stands for the power intensity, $d s$ for the line fire length, and $q$ for the power per unit volume. The integral was obtained in the prismatic flame region with base equal to flame height. A Gaussian distribution of the source depth $q$ function was assumed and adjustments were made in order to satisfy (17a), (17b), and (17c) on the computational domain.

3.2.1. Line Grass Fire. The first scenario corresponds to the examples given by $[6,86]$. The problem consists in estimating the maximum spot fire distance from a heading fire in short grass, with intensity of $2000 \mathrm{~kW} / \mathrm{m}$ when the wind speed at $10 \mathrm{~m}$ height is $5 \mathrm{~m} / \mathrm{s}$. The vegetation height is equal to $2.5 \mathrm{~m}$ and the vegetation area density corresponds to a triangular vertical distribution with maximum value of 0.5 . The inlet velocity is a power law (1/7) and linear stratified $0.003 \mathrm{~K} / \mathrm{m}$ above $30 \mathrm{~m}$. The flame height was estimated from Rothermel correlations [41] to be $2.6 \mathrm{~m}$ height and the line fire length was $60 \mathrm{~m}$. The volumetric heat source was allocated in the prismatic volume with equilateral triangular cross section of $3 \mathrm{~m}$ height (predicted by Rothermel correlations). The strength mean value was $49 \mathrm{~kW} / \mathrm{m}^{3}$ and on the ground $10 \mathrm{~kW} / \mathrm{m}^{2}$ to ensure the $2000 \mathrm{~kW} / \mathrm{m}$ fire. The inlet velocity and temperature field were perturbed at each time step according to

$$
\begin{gathered}
T=T_{0}+0.1 \xi\left(1-\frac{y}{y^{*}}\right) T_{*}, \\
U_{i}=U_{i}+0.1 \xi\left(1-\frac{y}{y^{*}}\right) W_{*},
\end{gathered}
$$

where $\xi$ is a Gaussian random number with zero mean and unit variance and the convective scale $W_{*}=\left(\beta g Q Z_{i o}\right)^{1 / 3}$ and $T_{*}=Q_{s} / W_{*}$. This procedure is required because no homogeneous directions can be considered and a velocity inlet profile is required for the phenomenon under consideration.

A grid of $64 \times 64 \times 64$ nodes discretizes the computational domain of $1000 \times 300$ metres in the horizontal plane and 250 metres in the vertical direction. The mesh is nonuniform distributed on the ground vicinity with $1 \mathrm{~m}$ resolution and on the line fire region; typically 8000 time iterations (16minute real time) were performed. Particles were released with zero velocity inside the region where heat release was prescribed. Ten particle sizes classes were considered from 0.5 to $9.5 \mathrm{~mm}$ of diameter and for each class 50 particles were randomly distributed around the spanwise control volumes. The particles may experience ground deposit or burnout or exiting the domain and when this occurs, a new particle was inserted in the heat release region. A total of 500 particles were always tracked in each time step during 6000 time steps and the total number of particle ground depositions was around 20000. The particle initial density was $200 \mathrm{~kg} / \mathrm{m}^{3}$ and the percentage in mass of char, ash, water, and pyrolysis was $70 \%, 20 \%, 1 \%$, and $4 \%$, respectively.

Figure 6(a) shows a three-dimensional view of the scalar smoke concentration field. The buoyant flow under cross flow originates two characteristic vortex structures and far away from the source the corotating vortex pair originates two plume tubes where the smoke concentration is maximum. For visualization purposes the smoke concentration equal to the unity was prescribed in the heat release volume.

The Albini model was programmed and their correlations for vegetation fires or torching trees give the maximum spotting distance and for the torching trees the model output includes also the particle diameter. However for vegetation fires Albini model does not predict the particle size diameter that corresponds to the maximum spotting distance. Another remark is concerned with the prescription of the fire and also its behaviour compared with a real situation where strong flame oscillations are present and taken into account by Albini. No effort was made to consider unsteady volumetric heat release sources. The predicted puffing of the plume could only affect very small particles.

Figure 6(b) shows the coordinates of the point where the particle attains the maximum altitude along their particle trajectory and the spotting distance of the corresponding particle. For each particle size class the maximum location depends strongly on its initial position. If the buoyant column does not capture the particle its trajectory is very short. As the total number of particles was around 20000 it is believed that a good statistical description of the source release positions was covered. According to Albini model the particle reaches the maximum altitude of $68 \mathrm{~m}$ for this scenario. From the present predictions this should correspond to particles around $2 \mathrm{~mm}$ diameter. Particles smaller than $1 \mathrm{~mm}$ burn during the flight according to the combustion model considered. Form Figure 6(b) it is possible to conclude that the particles trapped higher up in the plume are taken further downstream.

The results corresponding to the probability for ground deposition are shown in Figure 6(c). One should mention that the probability was evaluated by counting, for each class, the particles that deposit in each longitudinal slice of $2 \mathrm{~m}$ length and the number divided by the total of particles that deposit for each class. Consequently if a larger slice size was selected the probability would increase but with a similar distribution. Nevertheless Figure 6(c) shows that particles deposit close to the inlet due to large size or those with a small size released at a too low initial position or they fall out of the convection column. Figure 6(c) shows that relatively only few particles spot far than 200 metres. But there are differences in propagation distance among particles released randomly at the same height. The maximum predicted spotting distance was 400 metres for 1.5 and $2.5 \mathrm{~mm}$ spherical diameter. The Albini model predictions, corrected by [86], indicate that the maximum spotting distance is $450 \mathrm{~m}$.

The second test case corresponds to a wind-driven fire in chaparral when the wind speed at $10 \mathrm{~m}$ height is $20 \mathrm{~m} / \mathrm{s}$ and the fire intensity is $50000 \mathrm{~kW} / \mathrm{m}$. This corresponds to a severe surface fire with very high intensity and very strong 


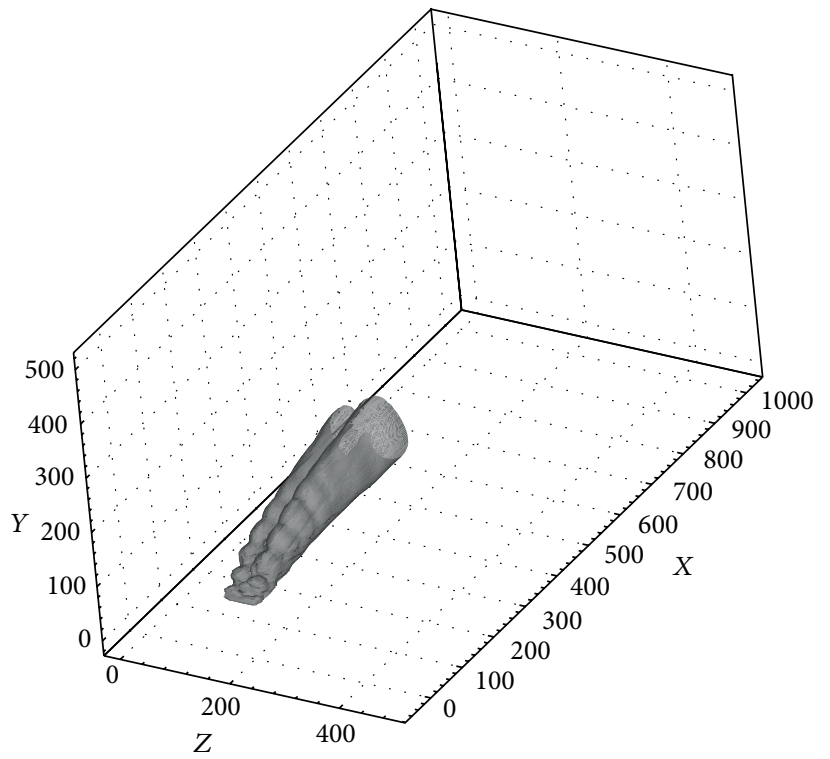

(a)

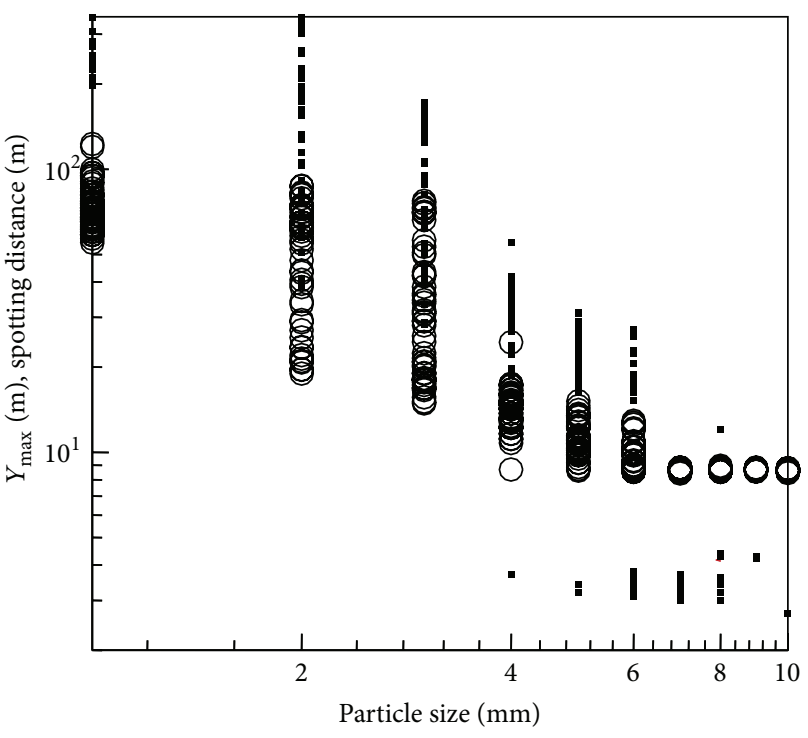

- $X$

$\bigcirc Y_{\max }$

(b)

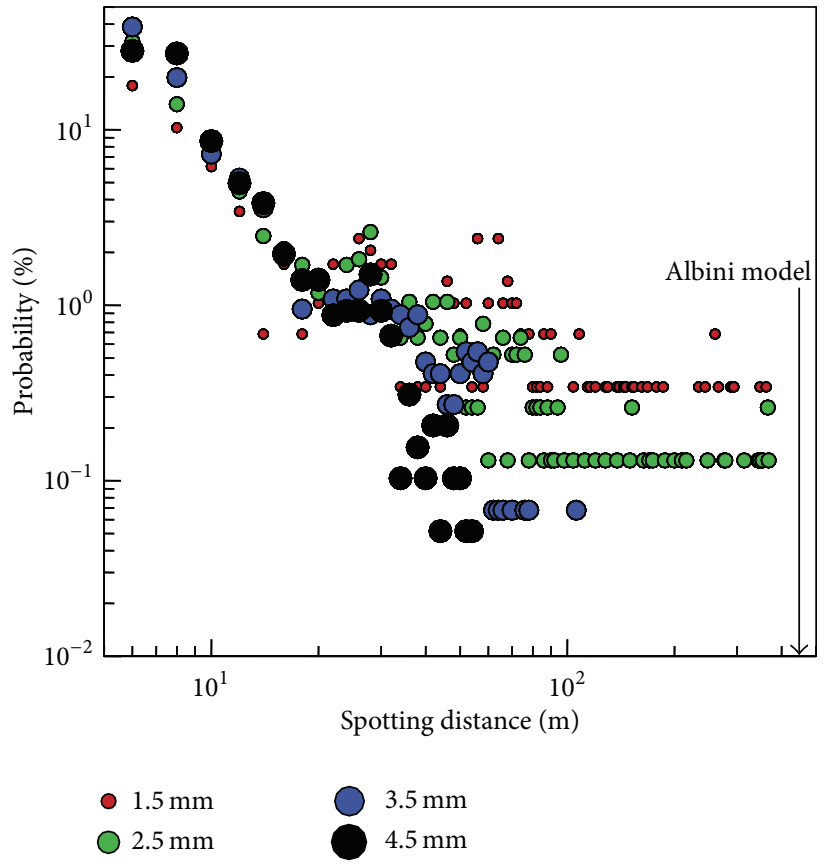

(c)

FIGURE 6: (a) Smoke scalar concentration for $20000 \mathrm{~kW} / \mathrm{m}$ short grass fire; (b) maximum height and longitudinal distances during particle trajectory as a function of particle size; and (c) probability of particles spotting distances as a function of particle size.

wind. Large spotting distances might be expected in light of the results from the first example. Conditions similar to the previous example were used but the computational domain extends to $3 \mathrm{~km}$ in the longitudinal direction and by $500 \mathrm{~m}$ in both the spanwise and vertical directions. A $64 \times 64 \times 64$ coarse grid was used and the vegetation was assumed to have $4 \mathrm{~m}$ height and the flames were assumed to have $10 \mathrm{~m}$ height.
A volumetric heat release rate of $508 \mathrm{~kW} / \mathrm{m}^{3}$ was prescribed in the flame region of the 100-metre line fire.

Figure 7(a) show the three-dimensional view of smoke concentration up to $1 \mathrm{~km}$ from the source. Several distinct types of coherent vortical structures have been observed in our simulations. It is possible to identify the rolling up shear-layer ("hanging" the Kelvin-Helmholtz instability) like 


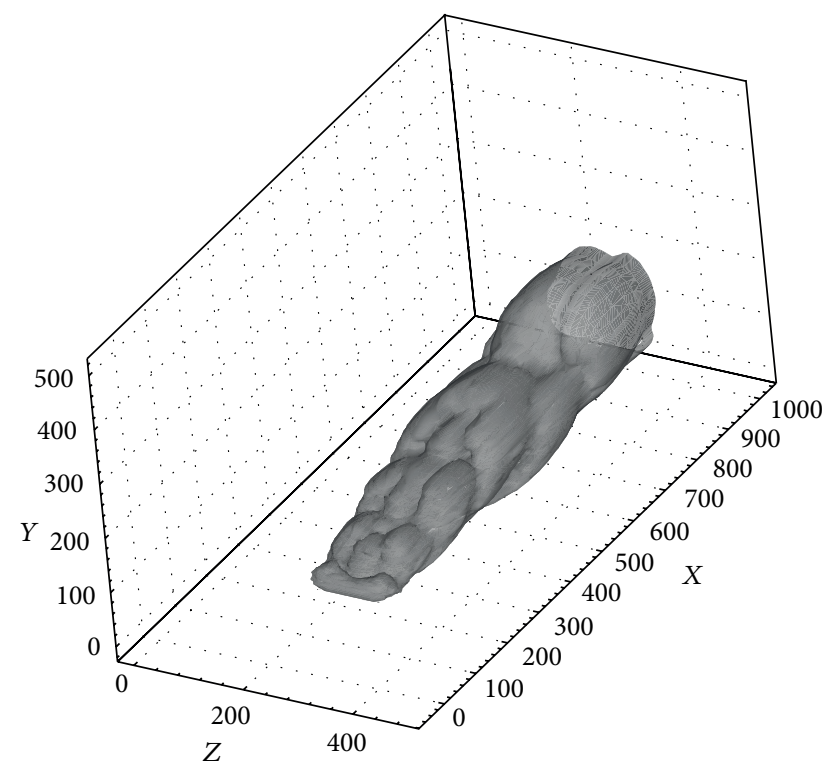

(a)

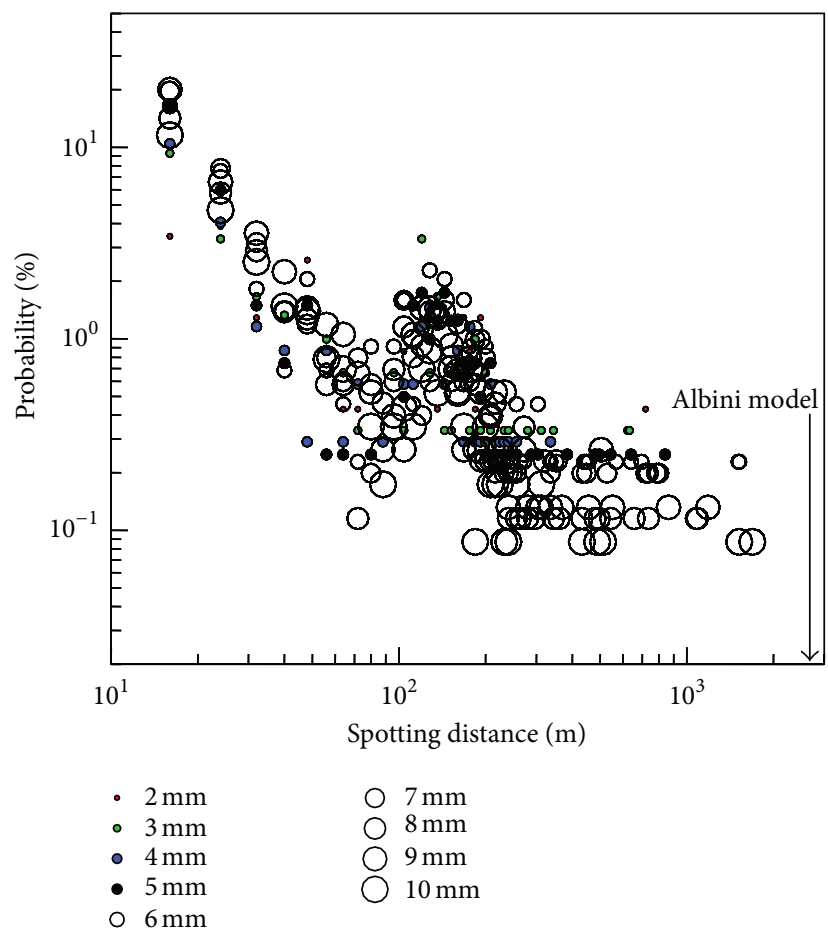

(b)

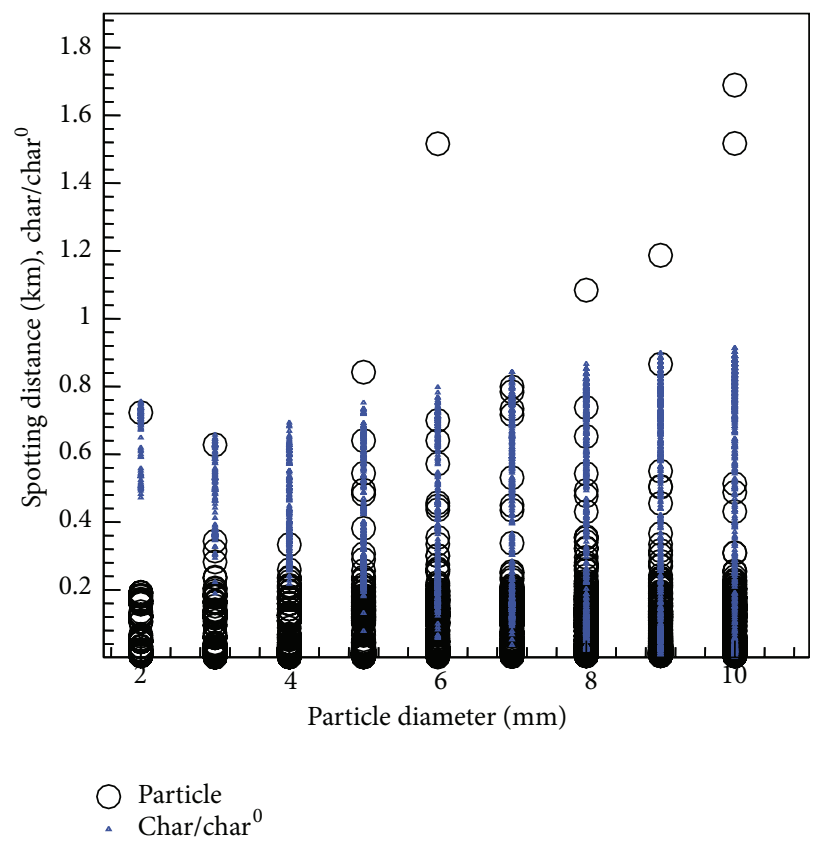

(c)

Figure 7: (a) Smoke scalar concentration for $50000 \mathrm{~kW} / \mathrm{m}$ short grass fire; (b) probability of particles spotting distances as a function of particle size; and (c) particles spotting distances and char content as a function of particle size.

the one described by [87]. Due to the long line fire length the vortical structures corresponding to the counterrotating vortex air, plume did not yet bifurcate. It is also possible to distinguish the incipient edge vortices, at the windward corners of the line fuel surface and located near the ground surface. Finally in the wake, not visible in the figure, there are wake vortices that interact with the ground for this strong wind.

Figure 7(b) shows the spotting distances probability as a function of particle size diameter valuated by the number of particles that deposit in $10 \mathrm{~m}$ longitudinal slice. Particles smaller than $2 \mathrm{~mm}$ diameter burn out during the flight. Due 
to the strong wind and convection column larger particles may be transported to larger distances without burning. Albini model predicts the maximum spotting distance at $2820 \mathrm{~m}$. The present 3D predictions show spotting distances up to $1800 \mathrm{~m}$ that are smaller but under the present plume flow coherent structure the trapped particles will describe trajectories that could not be captured by simplified classic models. Firebrand motion is very sensitive to the variable flow field surrounding it that is governed by the fire-atmosphere dynamical system.

Figure 6(b) also shows that the distribution of spot fires decreases rapidly with distance downwind of the fires and can be described using a negative exponential function (see Figure 6(b)), while Figure 7(b) denotes around $100 \mathrm{~m}$ a slight increase followed by a rapid decrease. It may be due to the strong vertical flows.

Figure 7(c) shows the spotting distance, as well as the char content divided by initial char mass. One should observe that the ordinates axis displays two scales: (i) the spotting distance units in $\mathrm{km}$ and (ii) the char particle content at spotting divided by the initial particle content; this ratio is represented in the scale 0 to 1 . Small particles deposit with high char content and large particles deposit with char percentages that range almost from zero (burnout) to $80 \%$, due to different residence lifetimes along their trajectories. Particles with low char mean that their density is lower and consequently for the same drag are likely to be transported further downstream.

3.2.2. Torching Trees. The calculations correspond to the Rothermel example [73] that uses the Albini model version to calculate the maximum spotting distance from torching trees. The first example corresponds to a single Grand Fir torching tree of $50 \mathrm{~m}$ height in a forest with the other tree's $43 \mathrm{~m}$ height and the wind speed of $9 \mathrm{~m} / \mathrm{s}$ at $6 \mathrm{~m}$ height. The heat of $38 \mathrm{~kW} / \mathrm{m}^{3}$ was released in a cone of $12 \mathrm{~m}$ diameter and 40-metre height above 10-metre ground level to which a power of $180 \mathrm{MW}$ estimated from Rothermel correlations of burning speed and fuel mass available corresponds. However the author is not certain about the volumetric heat release of a Grand Fir torching tree under the wind velocity considered.

The instantaneous cross section planes of scalar smoke concentration display a horseshoe-like structure with counterrotating vortices. Figure 8(a) shows the maximum spotting distance for the single tree example. Albini model predicts the maximum spotting distance of $560 \mathrm{~m}$ and corresponding to a particle diameter of $4.9 \mathrm{~mm}$. However Albini assumed the drag coefficient of an infinite cylindrical particle shape. A simple balance between drag and weight forces shows that a cylinder may have a diameter 1.9 times bigger than the spherical diameter. The predictions for spherical particles show that $3 \mathrm{~mm}$ particles may reach a maximum distance of $600 \mathrm{~m}$ and $2 \mathrm{~mm}$ particle $900 \mathrm{~m}$ and consequently the present predictions are in satisfactory agreement with Albini model.

Figure 8(b) shows three different quantities. The first is the spotting distance in $\mathrm{km}$ units. The second is the particle ratio of char mass at deposition to its initial value in a scale between 0 and 1 and the third is the particle average temperature relative to initial $973 \mathrm{~K}$, also in the scale between
0 and 1 . The predictions show that larger particles deposit with a higher temperature than the small ones due to the shorter flight time and less heat release to the cold ambient. The spreading of the particle char content increases with particle size. Figure 8(c) shows the dependence of char on particle spotting distance denoting that the particles that travel more have consumed most of the char as it would be expected, but the $10 \mathrm{~mm}$ particles have the highest char variability at deposition. This information will be valuable for probabilistic ignition models that account for vegetation, moister content, and so forth. The dependence of char content on temperature is shown in Figure 8(d) denoting that larger particles have a lower char content and a wide range of temperatures than small particles that keep the char at a high value and cool down very fast. This is consequence of the combustion model constants used and other values would produce different results, but no data about real spotting material combustion (leaves; fruits; etc.) was found.

The second example corresponds to four torching Grand Fir trees aligned in the spanwise direction with 12-metre spacing. Figure 9 (a) shows the spotting distances. The Albini model predicts $780 \mathrm{~m}$ for a $7.4 \mathrm{~mm}$ cylindrical particle diameter. The present predictions suggest that the maximum spotting distance in between 700 and $800 \mathrm{~m}$ is reachable by 1.5 and $2.5 \mathrm{~mm}$ particles. The spotting distances and the corresponding particles char and temperature for four Grand Fir torching trees are represented in Figure 9(b). The average char content decreases with particle diameter, but its variability increases similarly to the previous example of a single torching tree.

\section{Conclusion Remarks}

In this work particle spotting distances were predicted with a coupled fire-atmosphere LES simulation. A volumetric heat source was used to simulate the fire and LES of the wind over and through homogeneous vegetation was conducted with the SGS kinetic model. This model was selected because it captures satisfactorily the mean flow and temperature effects that may be relevant to calculate particle spotting distances in different atmospheric boundary layer conditions: weakly unstable, neutral, and stratified.

The maximum spotting distance obtained with the Albini based correlation model is compared with the corresponding distance obtained from thousands of simulated particles in the 3D wind field. Classical examples were considered as benchmark test cases corresponding to vegetation line fires and torching trees reported by the pioneering researchers Rothermel and Albini.

The particle's initial position was prescribed randomly in all flame volumes and for the low intensity vegetation fire line the agreement between the two very different models is quite surprising, with the maximum spotting distances differing only by $10 \%$. This was obtained from a wide class of particle sizes that are located randomly around the fire line, changing density during flight path and so forth, and cannot be interpreted as there are always little things happening that seem to coincide with the target result. Albini model is 


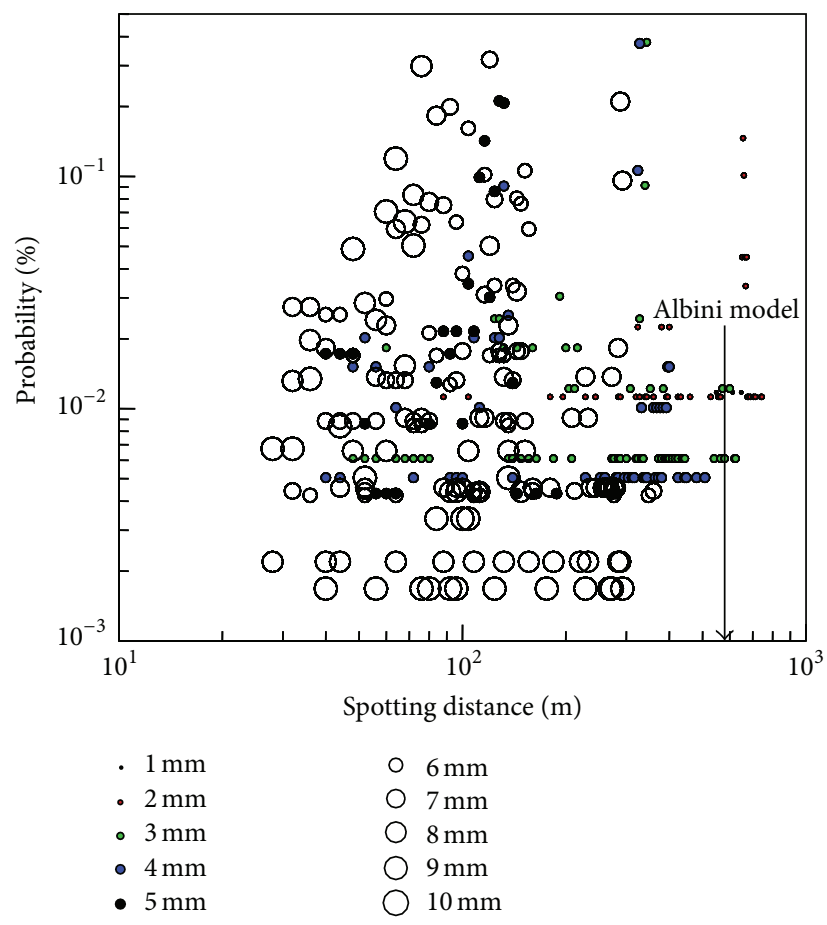

(a)

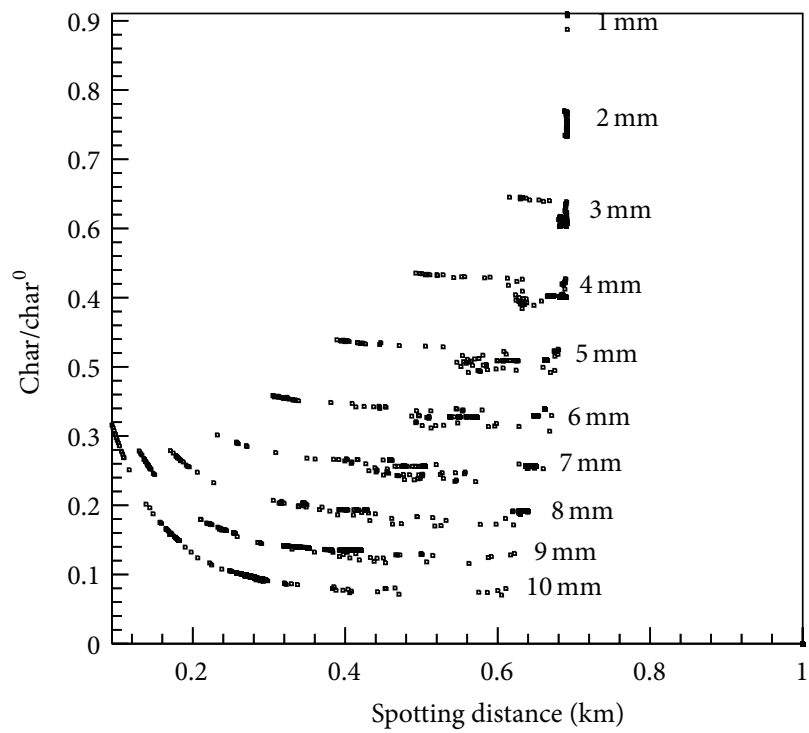

(c)

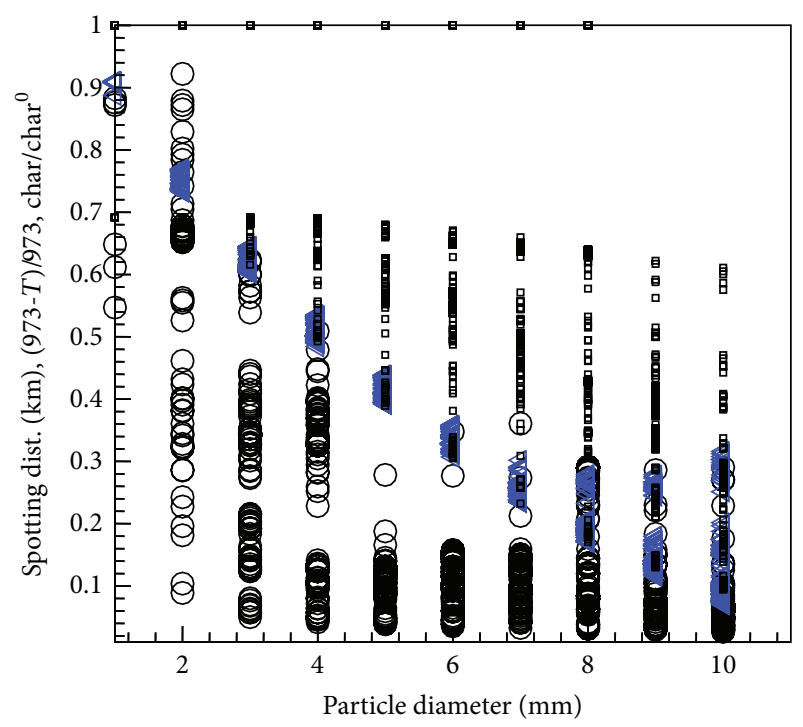

Particle

$\triangleleft(973-T) / 973$

- Char $/$ char $^{0}$

(b)

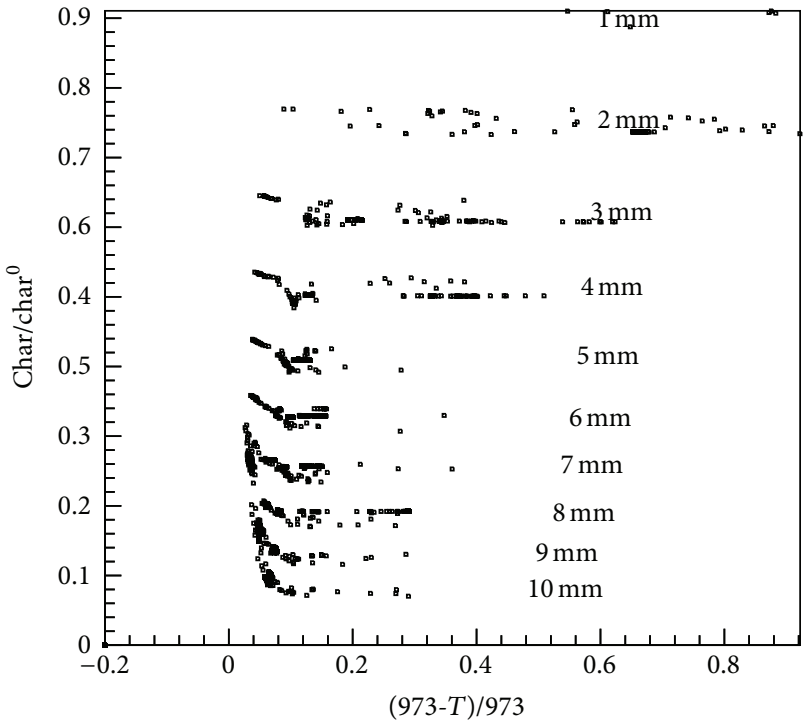

(d)

FIGURE 8: Single torching tree results: (a) spotting distance; (b) char, temperature, and spotting distance as a function of particle size; (c) char as a function of particle spotting distance; and (d) particle char as a function of particle temperature.

very popular in forest fire research and it is a simple integral model to predict the maximum spotting distance. The present work shows that for some cases it is in agreement with $3 \mathrm{D}$ multiphysics model predictions.

For the strong wind and high intensity, $50000 \mathrm{~kW} / \mathrm{m}$, vegetation fire where the predictions show a shorter maximum spotting distance, large differences are present between the two models and this may be attributed to the complex vortical flows formed or to the different particle combustion model that changes the particle density and alters the particle relaxation time.

The present predictions show also that the particles deposit from the source to the maximum spotting distance, in an inverted exponential function, and most of the particles deposit in the fire vicinity. Some of them were not entrained by the convection column and have a short flight path. In addition to the cases investigated particles up to $10 \mathrm{~mm}$ diameter are able to travel several hundred metres. The probability 


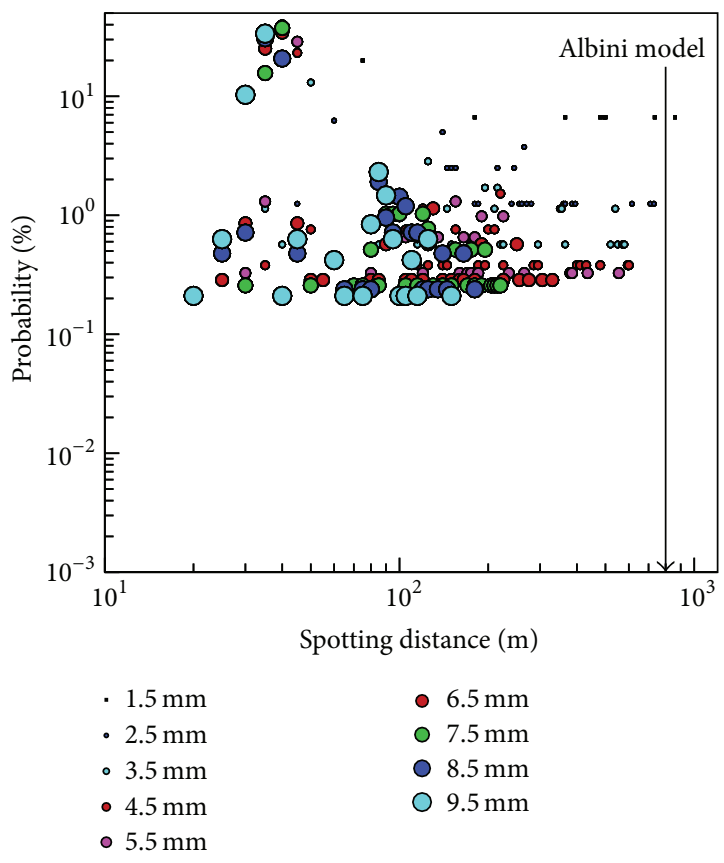

(a)

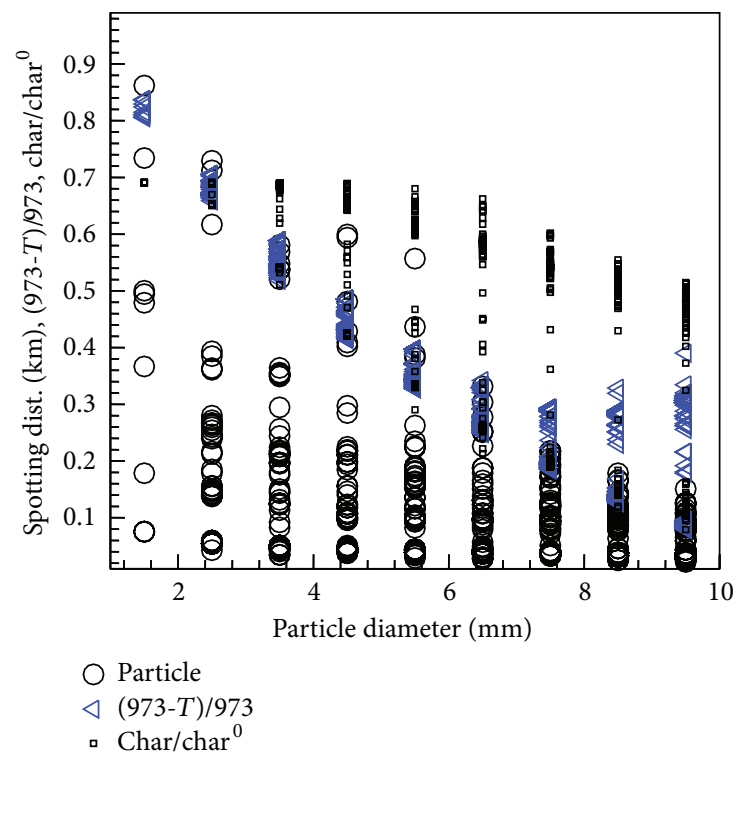

(b)

FIGURE 9: Four torching trees: (a) particle spotting distance; (b) char, temperature, and spotting distance as a function of particle size.

to reach longer distances increases for particles in the range 2 to $4 \mathrm{~mm}$, but low probability events may transport a larger particle, $10 \mathrm{~mm}$ close to the maximum spotting distance. This is a stochastic phenomenon that should be in the future considered by uncertainty quantification prediction tools.

Significant different assumptions have been made; several of them may be improved and made closer to the reality, namely, the particle combustion model for specific vegetation debris. The unsteady fire structure and modelling may be affected by the specific cases in question, the particle drag or spherical shape, and so forth. Another important influencing factor is the local geophysical and atmospheric conditions that may influence the plume structure. Others may be more easily solved by those with supercomputers access such as grid resolution or improvements in the heterogeneity of the fuel and the structure of mixed fuel types vegetation and terrain topology. The foreseeable continuous increase in speed and memory of the computers favours the development and application of coupled fire-atmosphere LES models because it increases the scope of current empirical or semiempirical operational models.

\section{Conflict of Interests}

The authors declare that there is no conflict of interests regarding the publication of this paper.

\section{Acknowledgments}

This work was supported by Fundação para a Ciência e Tecnologia (FCT, Portugal), through IDMEC, under LAETA,
Project UID/EMS/50022/2013. The third author would like to thank the support received by Fundação para a Ciência e Tecnologia (FCT, Portugal) under the project "ExtremePTDC/EMEMFE/11343/2009." The last author would like to acknowledge the support received during his Ph.D. study from Fundação para a Ciência e Tecnologia (FCT, Portugal) (Grant SFRH/BD/48150/2008 cofinanced by POPH/FSE).

\section{References}

[1] E. K. Noonan-Wright, T. S. Opperman, M. A. Finney et al., "Developing the US wildland fire decision support system," Journal of Combustion, vol. 2011, Article ID 168473, 14 pages, 2011.

[2] A. A. Ager, N. M. Vaillant, and M. A. Finney, "Integrating fire behavior models and geospatial analysis for wildland fire risk assessment and fuel management planning," Journal of Combustion, vol. 2011, Article ID 572452, 19 pages, 2011.

[3] P.-A. Santoni, A. Sullivan, D. Morvan, and W. E. Mell, "Forest fire research: the latest advances tools for understanding and managing wildland fire," Journal of Combustion, vol. 2011, Article ID 418756, 2 pages, 2011.

[4] C. S. Tarifa, P. P. Del Notario, and F. G. Moreno, "On the flight paths and lifetimes of burning particles of wood," Proceedings of the Combustion Institute, vol. 10, no. 1, pp. 1021-1037, 1965.

[5] S.-L. Lee and J. M. Hellman, "Firebrand trajectory study using an empirical velocity-dependent burning law," Combustion and Flame, vol. 15, no. 3, pp. 265-274, 1970.

[6] F. A. Albini, "Spot fire distance from burning trees-a predictive model," Tech. Rep. INT-56, USDA, Intermountain Forest and Range Experiment Station, 1979.

[7] F. A. Albini, "A model for the wind-blown flame from a line fire," Combustion and Flame, vol. 43, pp. 155-174, 1981. 
[8] F. A. Albini, "Potential spotting distance from wind-driven surface fires," Research Note INT-309, US Department of Agriculture, Forest Service Intermountain Forest and Range Experiment Station, Ogden, Utah, USA, 1983.

[9] F. A. Albini, "Transport of firebrands by line thermals," Combustion Science and Technology, vol. 32, no. 5-6, pp. 277-288, 1983.

[10] F. A. Albini, M. E. Alexander, and M. G. Cruz, "A mathematical model for predicting the maximum potential spotting distance from a crown fire," International Journal of Wildland Fire, vol. 21, no. 5, pp. 609-627, 2012.

[11] R. C. Rothermel, "A mathematical model for predicting fire spread in wildland fuels," Research Report, USDA-FS, Ogden, Utah, USA, 1972.

[12] R. E. Burgan and R. C. Rothermel, "BEHAVE: fire behavior prediction and fuel modeling system-fuel subsystem," General Technical Report INT-167, USDA Forest Service, Intermountain Forest and Range Experimental Station, Ogden, Utah, USA, 1984.

[13] P. L. Andrews, "Behave: fire behavior prediction and fuel modeling system-burn subsystem. Part 1," General Technical Report INT-194, USDA Forest Service, Intermountain Forest and Range Experimental Station, Ogden, Utah, USA, 1986.

[14] J. R. Coleman and A. L. Sullivan, "A real-time computer application for the prediction of fire spread across the Australian landscape," Simulation, vol. 67, no. 4, pp. 230-240, 1996.

[15] D. X. Viegas, "Forest fire propagation," Philosophical Transactions of the Royal Society A: Mathematical, Physical and Engineering Sciences, vol. 356, no. 1748, pp. 2907-2928, 1998.

[16] E. Pastor, L. Zárate, E. Planas, and J. Arnaldos, "Mathematical models and calculation systems for the study of wildland fire behaviour," Progress in Energy and Combustion Science, vol. 29, no. 2, pp. 139-153, 2003.

[17] M. A. Finney and S. S. McAllister, "A review of fire interactions and mass fires," Journal of Combustion, vol. 2011, Article ID 548328, 14 pages, 2011.

[18] C.-P. Mao, A. C. Fernandez-Pello, and J. A. C. Humphrey, "An investigation of Steady Wall-Ceiling and partial Enclosure fires," Journal of Heat Transfer, vol. 106, no. 1, pp. 221-228, 1984.

[19] G. Cox and S. Kuman, "Field modeling of fire in forced ventilated enclosures," Combustion Science and Technology, vol. 52, pp. 7-23, 1987.

[20] D. Drysdale, An Introduction to Fire Dynamics, Wiley, Chichester, UK, 2nd edition, 1998.

[21] V. K. Schilling, "A parameterization for modelling the meteorological effects of tall forests - a case study of a large clearing," Boundary-Layer Meteorology, vol. 55, no. 3, pp. 283-304, 1991.

[22] R. H. Shaw and U. Schumann, "Large-eddy simulation of turbulent flow above and within a forest," Boundary-Layer Meteorology, vol. 61, no. 1-2, pp. 47-64, 1992.

[23] G. Gross, Numerical Simulation of Canopy Flows, Springer, Berlin, Germany, 1993.

[24] M. G. Inclan, R. Forkel, R. Dlugi, and R. B. Stull, "Application of transilient turbulent theory to study interactions between the atmospheric boundary layer and forest canopies," BoundaryLayer Meteorology, vol. 79, no. 4, pp. 315-344, 1996.

[25] A. Wenzel, N. Kalthoff, and V. Horlacher, "On the profiles of wind velocity in the roughness sublayer above a coniferous forest," Boundary-Layer Meteorology, vol. 84, no. 2, pp. 219-230, 1997.

[26] M. R. Raupach and A. S. Thom, "Turbulence in and above plant canopies," Annual Review of Fluid Mechanics, vol. 13, pp. 97-129, 1981.
[27] D. D. Baldocchi and T. P. Meyers, "Turbulence structure in a deciduous forest," Boundary-Layer Meteorology, vol. 43, no. 4, pp. 345-364, 1988.

[28] Z. Li, J. D. Lin, and D. R. Miller, "Air flow over and through a forest edge: a steady-state numerical simulation," BoundaryLayer Meteorology, vol. 51, no. 1-2, pp. 179-197, 1990.

[29] U. Svensson and K. Häggkvist, "A two-equation turbulence model for canopy flows," Journal of Wind Engineering and Industrial Aerodynamics, vol. 35, no. 1-3, pp. 201-211, 1990.

[30] M. H. Kobayashi, J. C. F. Pereira, and M. B. B. Siqueira, "Numerical study of the turbulent flow over and in a model forest on a 2D hill," Journal of Wind Engineering and Industrial Aerodynamics, vol. 53, no. 3, pp. 357-374, 1994.

[31] G. G. Katul, L. Mahrt, D. Poggi, and C. Sanz, "One- and two-equation models for canopy turbulence," Boundary-Layer Meteorology, vol. 113, no. 1, pp. 81-109, 2004.

[32] A. S. Lopes, J. M. L. M. Palma, and J. V. Lopes, "Improving a two-equation turbulence model for canopy flows using largeeddy simulation," Boundary-Layer Meteorology, vol. 149, no. 2, pp. 231-257, 2013.

[33] J. W. Deardorff, "A three-dimensional numerical investigation of the idealized planetary boundary layer," Geophysical Fluid Dynamics, vol. 1, no. 3-4, pp. 377-410, 2008.

[34] P. J. Mason, "Large-eddy simulation: a critical review of the technique," Quarterly Journal-Royal Meteorological Society, vol. 120, no. 515, pp. 1-26, 1994.

[35] H. R. Baum, R. G. Rehm, and J. P. Gore, "Transient combustion in a turbulent eddy," in Proceedings of the 23rd International Symposium on Combustion, pp. 715-722, The Combustion Institute, Pittsburgh, Pa, USA, 1990.

[36] K. B. McGrattan, H. R. Baum, and R. G. Rehm, "Large Eddy simulations of smoke movement," Fire Safety Journal, vol. 30, no. 2, pp. 161-178, 1998.

[37] H. R. Baum and B. J. McCaffrey, "Fire induced flow fieldtheory and experiment," in Proceedings of the 2nd International Symposium on Fire Safety Science, pp. 129-148, Hemisphere, New York, NY, USA, June 1989.

[38] K. B. McGrattan, H. R. Baum, and R. G. Rehm, "Numerical simulation of smoke plumes from large oil fires," Atmospheric Environment, vol. 30, no. 24, pp. 4125-4136, 1996.

[39] M. Schatzmann, "An integral model of plume rise," Atmospheric Environment, vol. 13, no. 5, pp. 721-731, 1979.

[40] G. A. Davidson, "Gaussian versus top-hat profile assumptions in integral plume models," Atmospheric Environment, vol. 20, no. 3, pp. 471-478, 1986.

[41] G. N. Mercer and R. O. Weber, "Plumes above line fires in a cross wind," in Proceedings of the 2nd International Conference on Forest Fire Research, D. X. Viegas, Ed., Coimbra, Portugal, November 1994.

[42] J. Trelles, K. B. McGrattan, and H. R. Baum, "Smoke dispersion from multiple fire plumes," AIAA Journal, vol. 37, no. 12, pp. 1588-1601, 1999.

[43] H. Schmidt and U. Schumann, "Coherent structure of the convective boundary layer derived from large-eddy simulations," Journal of Fluid Mechanics, vol. 200, pp. 511-562, 1989.

[44] X.-Q. Chen and J. C. F. Pereira, "Computational modeling of two-phase flows with particles and droplets," Trends in Heat, Mass \& Momentum Transfer, vol. 5, pp. 81-99, 1999.

[45] E. Koo, P. J. Pagni, D. R. Weise, and J. P. Woycheese, "Firebrands and spotting ignition in large-scale fires," International Journal of Wildland Fire, vol. 19, no. 7, pp. 818-843, 2010. 
[46] I. K. Knight, "The design and construction of a vertical wind tunnel for the study of untethered firebrands in flight," Fire Technology, vol. 37, no. 1, pp. 87-100, 2001.

[47] S. L. Manzello, J. R. Shields, T. G. Cleary et al., "On the development and characterization of a firebrand generator," Fire Safety Journal, vol. 43, no. 4, pp. 258-268, 2008.

[48] M. Almeida, D. X. Viegas, A. I. Miranda, and V. Reva, "Effect of particle orientation and of flow velocity on the combustibility of Pinus pinaster and Eucalyptus globulus firebrand material," International Journal of Wildland Fire, vol. 20, no. 8, pp. 946962, 2011.

[49] A. Hölzer and M. Sommerfeld, "New simple correlation formula for the drag coefficient of non-spherical particles," Powder Technology, vol. 184, no. 3, pp. 361-365, 2008.

[50] S. Suzuki, S. L. Manzello, M. Lage, and G. Laing, "Firebrand generation data obtained from a full-scale structure burn," International Journal of Wildland Fire, vol. 21, no. 8, pp. 961-968, 2012.

[51] M. Zastawny, G. Mallouppas, F. Zhao, and B. van Wachem, "Derivation of drag and lift force and torque coefficients for non-spherical particles in flows," International Journal of Multiphase Flow, vol. 39, pp. 227-239, 2012.

[52] M. J. Antal Jr., H. L. Friedman, and F. E. Rogers, "Kinetics of cellulose pyrolysis in nitrogen and steam," Combustion science and technology, vol. 21, no. 3-4, pp. 141-152, 1980.

[53] J. P. Woycheese and P. J. Pagni, "Combustion models for wooden brands," in Proceedings of the 3rd International Conference on Fire Research and Engineering (ICFRE3 '99), pp. 53-71, Society of Fire Protection Engineers, Chicago, Ill, USA, October 1999.

[54] B. Benkoussas, J.-L. Consalvi, B. Porterie, N. Sardoy, and J.C. Loraud, "Modelling thermal degradation of woody fuel particles," International Journal of Thermal Sciences, vol. 46, no. 4, pp. 319-327, 2007.

[55] N. Sardoy, J.-L. Consalvi, B. Porterie, and A. C. FernandezPello, "Modeling transport and combustion of firebrands from burning trees," Combustion and Flame, vol. 150, no. 3, pp. 151169, 2007.

[56] J. Tomeczek, Coal Combustion, Kriger Publishing Company, Malabar, Fla, USA, 1994.

[57] C. Di Blasi, "Modeling chemical and physical processes of wood and biomass pyrolysis," Progress in Energy and Combustion Science, vol. 34, no. 1, pp. 47-90, 2008.

[58] A. F. Roberts, "A review of kinetics data for the pyrolysis of wood and related substances," Combustion and Flame, vol. 14, no. 2, pp. 261-272, 1970.

[59] A. M. Costa, J. C. F. Pereira, and M. Siqueira, "Numerical prediction of fire spread over vegetation in arbitrary 3D terrain," Fire and Materials, vol. 19, no. 6, pp. 265-273, 1995.

[60] T. L. Clark, J. Coen, and D. Latham, "Description of a coupled atmosphere-fire model," International Journal of Wildland Fire, vol. 13, no. 1, pp. 49-63, 2004.

[61] S. Bhutia, M. A. Jenkins, and R. Sun, "Comparison of firebrand propagation prediction by a plume model and a coupledfire/atmosphere large-eddy simulator," Journal of Advances in Modeling Earth Systems, vol. 2, article 4, pp. 1-15, 2010.

[62] J. P. Woycheese, P. J. Pagni, and D. Liepman, "Brand Lofting from large-scale fires," Journal of Fire Protection Engineering, vol. 10, no. 2, pp. 32-44, 1999.

[63] R. A. Anthenien, S. D. Tse, and A. C. Fernandez-Pello, "On the trajectories of embers initially elevated or lofted by small scale ground fire plumes in high winds," Fire Safety Journal, vol. 41, no. 5, pp. 349-363, 2006.
[64] X. Y. Zhou and J. C. F. Pereira, "Multidimensional model for simulating vegetation fire spread using a porous media submodel," Fire and Materials, vol. 24, no. 1, pp. 37-43, 2000.

[65] B. Porterie, D. Morvan, J. C. Loraud, and M. Larini, "Firespread through fuel beds: modeling of wind-aided fires and induced hydrodynamics," Physics of Fluids, vol. 12, no. 7, pp. 1762-1782, 2000.

[66] X. Zhou, S. Mahalingam, and D. Weise, "Experimental study and large eddy simulation of effect of terrain slope on marginal burning in shrub fuel beds," Proceedings of the Combustion Institute, vol. 31, pp. 2547-2555, 2007.

[67] W. Mell, M. A. Jenkins, J. Gould, and P. Cheney, "A physicsbased approach to modelling grassland fires," International Journal of Wildland Fire, vol. 16, no. 1, pp. 1-22, 2007.

[68] W. Mell, A. Maranghides, R. McDermott, and S. L. Manzello, "Numerical simulation and experiments of burning douglas fire trees," Combustion and Flame, vol. 156, no. 10, pp. 2023-2041, 2009.

[69] S. Kortas, P. Mindykowski, J. L. Consalvi, H. Mhiri, and B. Porterie, "Experimental validation of a numerical model for the transport of firebrands," Fire Safety Journal, vol. 44, no. 8, pp. 1095-1102, 2009.

[70] L. A. Oliveira, A. G. Lopes, B. R. Baliga, M. Almeida, and D. X. Viegas, "Numerical prediction of size, mass, temperature and trajectory of cylindrical wind-driven firebrands," International Journal of Wildland Fire, vol. 23, no. 5, pp. 698-708, 2014.

[71] E. Koo, R. R. Linn, P. J. Pagni, and C. B. Edminster, "Modelling firebrand transport in wildfires using HIGRAD/FIRETEC," International Journal of Wildland Fire, vol. 21, no. 4, pp. 396417, 2012.

[72] J.-B. Filippi, F. Bosseur, X. Pialat, P.-A. Santoni, S. Strada, and C. Mari, "Simulation of coupled fire/atmosphere interaction with the MesoNH-ForeFire models," Journal of Combustion, vol. 2011, Article ID 540390, 13 pages, 2011.

[73] R. C. Rothermel, "How to predict the spread and intensity of forest and range fires," Tech. Rep. INT-143, Intermountain Forest and Range Experiment Station, Ogden, Utah, USA, 1983.

[74] C. B. da Silva and J. C. F. Pereira, "The effect of subgrid-scale models on the vortices computed from large-eddy simulations," Physics of Fluids, vol. 16, no. 12, pp. 4506-4534, 2004.

[75] C. B. da Silva and J. C. F. Pereira, "Analysis of the gradientdiffusion hypothesis in large-eddy simulations based on transport equations," Physics of Fluids, vol. 19, no. 3, 2007.

[76] H. Schmidt, "Grobstruktur-simulation konvektiver Grenzschichten, Thesis," Report DFVLR-FB 88-30, DLR, University of Munich, Oberpfaffenhofen, Germany, 1988.

[77] J. Smagorinsky, "General circulation experiments with the primitive equations. I. The basic experiment," Monthly Weather Review, vol. 91, no. 3, pp. 99-164, 1963.

[78] P. Sagaut, Large Eddy Simulation for Incompressible Flows, Springer, Berlin, Germany, 2nd edition, 2002.

[79] B. Porterie, D. Moryan, J. C. Loraud, and M. Larini, "A multiphase model for predicting line fire propagation," in Proceedings of the 3rd International Conference on Forest Fire Research, 14th Conference on Fire and Forest Meteorology, vol. 1, pp. 343-360, Luso, Portugal, 1998.

[80] M. J. Antal, H. L. Friedman, and F. E. Rogers, "Kinetics of cellulose pyrolysis in nitrogen and steam," Combustion Science and Technology, vol. 21, no. 3-4, pp. 141-152, 1980.

[81] B. P. Leonard, "A stable and accurate convective modelling procedure based on quadratic upstream interpolation," Computer 
Methods in Applied Mechanics and Engineering, vol. 19, no. 1, pp. 59-98, 1979.

[82] F. Durst, J. C. F. Pereira, and C. Tropea, "The plane symmetric sudden-expansion flow at low Reynolds numbers," Journal of Fluid Mechanics, vol. 248, pp. 567-581, 1993.

[83] J. C. F. Pereira and J. M. M. Sousa, "Finite volume calculations of self-sustained oscillations in a grooved channel," Journal of Computational Physics, vol. 106, no. 1, pp. 19-29, 1993.

[84] J. P. Magalhães, D. M. S. Albuquerque, J. M. C. Pereira, and J. C. F. Pereira, "Adaptive mesh finite-volume calculation of 2D lidcavity corner vortices," Journal of Computational Physics, vol. 243, pp. 365-381, 2013.

[85] D. M. S. Albuquerque, J. M. C. Pereira, and J. C. F. Pereira, "Residual least squares error estimate for unstructured hadaptive meshes," Numerical Heat Transfer, Part B: Fundamentals, vol. 67, no. 3, pp. 187-210, 2015.

[86] C. H. Chase, Spotting Distance from Wind-Driven Surface Fires-Extensions of Equations for Pocket Calculations, Northen Forest Fire Laboratory, Missoula, Mont, USA, 1984.

[87] L. L. Yuan, R. L. Street, and J. H. Ferziger, "Large-eddy simulations of a round jet in crossflow," Journal of Fluid Mechanics, vol. 379, pp. 71-104, 1999. 

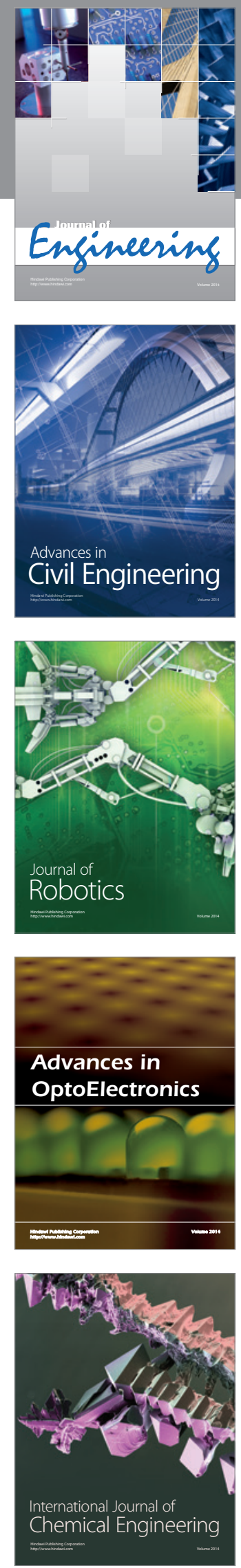

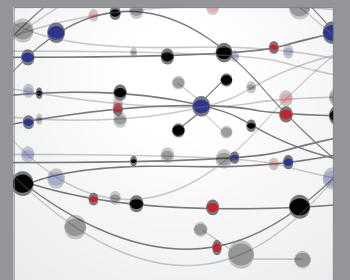

The Scientific World Journal
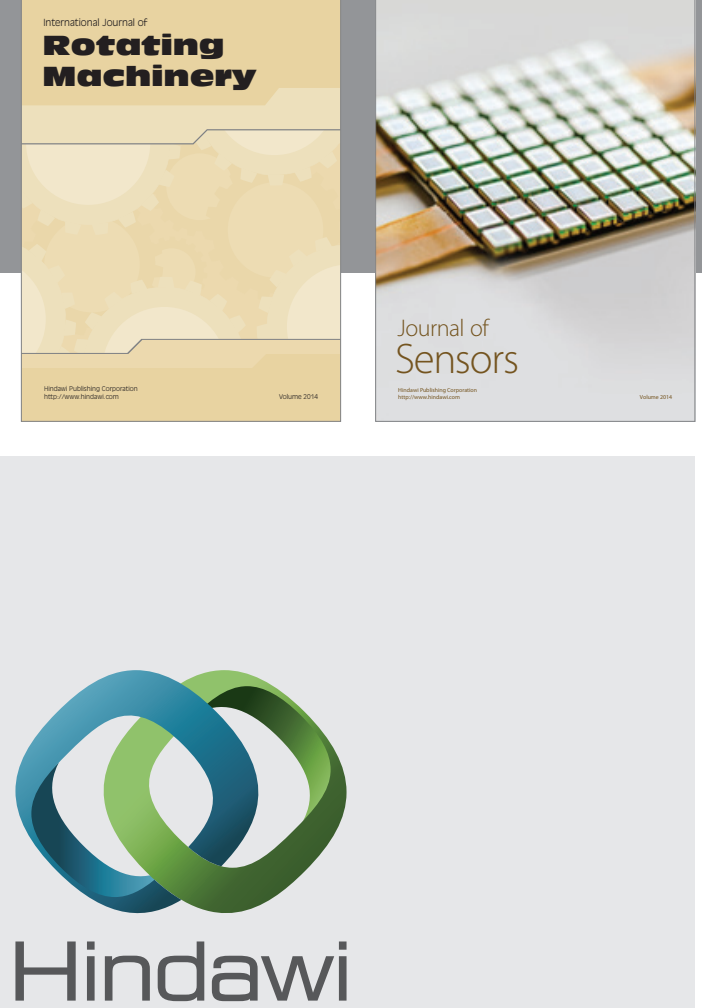

Submit your manuscripts at http://www.hindawi.com
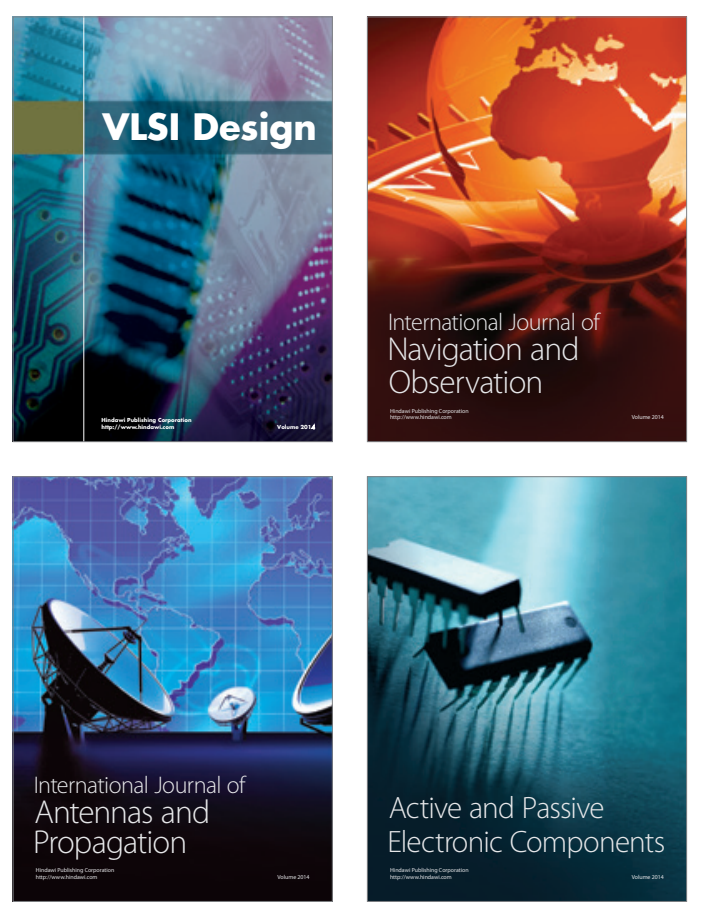
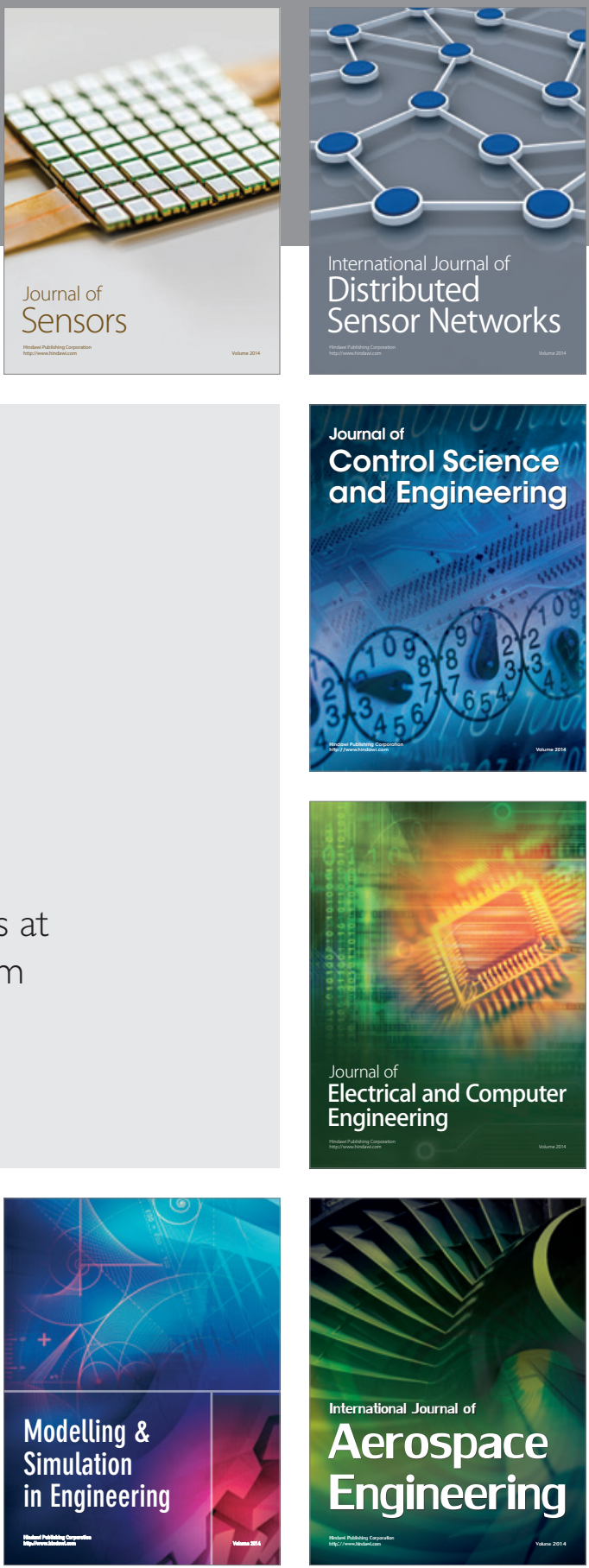

Journal of

Control Science

and Engineering
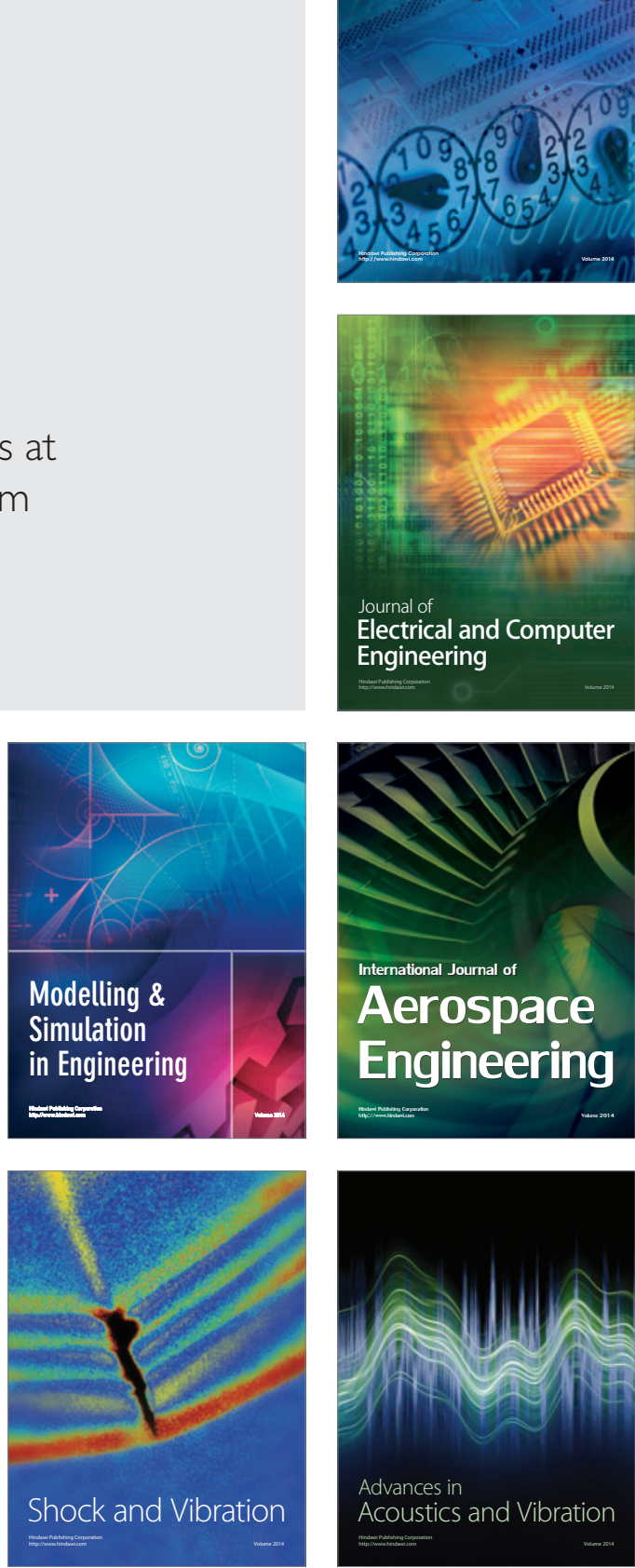